\title{
Prevalência de Sintomas Osteomusculares em Cobradores de Ônibus Coletivo em Uma Empresa na Cidade de Juazeiro do Norte - CE
}

\author{
Anny Caroline Costa Vieira ${ }^{1}$; Cristiane Marinho Uchôa Lopes ${ }^{2}$;Denise Leal Pires ${ }^{3}$; \\ Gilnara Rosana Pereira de Almeida ${ }^{4}$; Gislene Farias de Oliveira ${ }^{5}$
}

\begin{abstract}
Resumo: Os cobradores de ônibus são profissionais que realizam tarefas no dia-a-dia que requerem a utilização de movimentos e ações que são propícias a desencadear alterações e desconforto postural. Sintomas de distúrbios osteomusculares (SDO) torna-se um terrível problema de saúde no trabalho, podendo ser observada em indivíduos com diversas ocupações, até mesmo do setor de transporte. Dentro desse contexto houve o interesse em investigar acerca da saúde do trabalhador. O objetivo foi verificar a prevalência de sintomas osteomusculares relacionados ao trabalho em cobradores de uma empresa de ônibus coletivo na cidade de Juazeiro do Norte-CE. Trata-se de uma pesquisa de caráter observacional e de abordagem quantitativo-descritivo. A amostra foi composta por 30 cobradores de ônibus coletivos que tinham idade entre 21 e 58 anos, e que trabalhavam nessa função há mais de um ano. A pesquisa foi realizada dos dias 17 a 29 de setembro de 2012 no horário de 12:00h às 13:00h, os entrevistados assinaram o Termo de Consentimento Livre e Esclarecido (TCLE) e em seguida responderam ao questionário Nórdico dos Sintomas Osteomusculares versão adaptada por Serranheira et al. (2003). Os resultados encontrados mostraram em todos os segmentos avaliados pelo questionário houve relatos de sintomas osteomusculares, no entanto, a coluna como um todo, foi mais relevante em relação aos outros segmentos. Sendo que a coluna lombar $100,0 \%$ dos profissionais apresentou desconforto e dorsal $86,7 \%$, porém o que mostrou mais interferência no trabalho foi a região dorsal com $16,7 \%$ comparando-se com a lombar $13,3 \%$. Todos esses segmentos da coluna são acometidos, estando em terceiro lugar a cervical, segundo lugar a torácica e em primeiro lugar a lombar que por ventura essa é a região que mais sofre agressão por conta da postura sentada durante a jornada de trabalho desses profissionais. Pode-se concluir que há uma grande frequência de dores osteomusculares relacionada ao trabalho nos cobradores de ônibus. Sendo que a mais frequente dentre estas, a lombar justifica pelo fato dessa estrutura ser a mais acometida mediante a postura sentada.
\end{abstract}

Palavras-chaves: Cobradores de ônibus, sintomas, Jornada de Trabalho.

\section{Prevalence of musculoskeletal symptoms in collectors on a public bus company in the city of Juazeiro do Norte - CE.}

\begin{abstract}
The bus conductors are professionals who perform tasks on a day-to-day life that require the use of movements and actions that are prone to trigger discomfort and postural changes. Symptoms of musculoskeletal disorders (SDO) becomes a terrible health problem at work, and can be observed in individuals with different occupations, even the transportation sector. Within this context there was interest in investigating about the health of the worker. The objective was to determine the prevalence

\footnotetext{
${ }^{1}$ Graduação em Fisioterapia pela Faculdade Leão Sampaio. E-mail: anny_carol_15@hotmail.com;

${ }^{2}$ Graduação em Fisioterapia pela Faculdade Integrada do Ceará; Pós- graduação em Fisioterapia em Terapia Manual e Postural pelo Centro Universitário de Maringá - CESUMAR, Formação em Osteopatia pela Escola Brasileira de Osteopatia e Terapia Manual (EBOM), Especialista em Saúde Coletiva pela Universidade Federal de São Paulo (UNIFESP), Especialista em Docência do Ensino Superior pela Faculdade Leão Sampaio. Pós-graduada em Fisiologia do Exercício e Grupos Especiais pela Faculdade Leão Sampaio (FALS) e Mestre em Saúde Coletiva pela Universidade de Fortaleza (UNIFOR). Doutoranda em Biotecnologia em Saúde pela Rede Nordeste de Biotecnologia RENORBIO. Docente da Faculdade Leão Sampaio e da Estácio/FMJ. E-

${ }^{3}$ Fisioterapia pela Faculdade Leão Sampaio. E4

5 Doutorado em Psicologia Social. Professora da Universidade Federal do Cariri: E-mail: gislenefarias@gmail.com.
} 
and symptoms of work-related musculoskeletal collectors in a bus company in the city of collective Juazeiro-CE. This is a survey of observational and descriptive quantitative approach. The sample was composed of 30 collectors bus collectives were aged between 21 and 58 years, and worked in that role for over a year. The survey was conducted from 17 to 29 September 2012 between the hours of 12:00 to 13:00, the intrevistados signed an Informed Consent Form (ICF) and then responded to the questionnaire of the Nordic Musculoskeletal version adapted by Serranheira et al. (2003). The results showed in all segments assessed by questionnaire were no reports of musculoskeletal symptoms, however, the column as a whole was more important compared to other threads. Since the lumbar spine $100.0 \%$ of professionals had back discomfort and $86.7 \%$, but what was more interference in the work was the dorsal region with $16.7 \%$ compared with $13.3 \%$ the lumbar. All these segments of the spine are affected, being the third cervical, thoracic and secondly to the first lumbar that perhaps this is the region that was harmed because of the sitting posture during the workday these professionals. It can be concluded that there is a high frequency of work-related musculoskeletal pain in collectors bus. Since the most common among these, the lumbar justified by the fact that the structure be the most affected by the sitting posture.

Keywords: Collectors bus, symptoms, Workday.

\section{Introdução}

O trabalho é uma tarefa desenvolvida pelo homem no intuito de produzir riqueza. No entanto a história do trabalho dá inicio quando o homem sai em busca de elementos para suprir suas obrigações. Essa busca se repete, de acordo com a história, com a finalidade de continuar sobrevivendo. De acordo com que as necessidades pessoais a serem conquistada, crescem as necessidades criando as relações sociais que originam a visão histórica do trabalho (DELIBERATO, 2002).

Os cobradores de ônibus são profissionais que realizam tarefas no dia-a-dia, que exigem utilizações de movimentos e ações que são propicias a desencadear alterações e desconforto postural. Vale a pena ressaltar que com sua intensa jornada de trabalho os cobradores adotam uma postura errônea por longos períodos para permanecerem na mesma postura e adaptar-se ao posto de trabalho, também considerando-se os fatores externos, como poluição, barulho no trânsito, contato direto com o público e vibrações decorrentes do transporte, e causa de estresse que levam a uma alteraçãomusculoesquelética comprometendo então a saúde do trabalhador.

Diferentes aspectos, podemos comparar o homem a uma maquina humana, com pouca capacidade de desenvolver força, uma vez que seu sistema osteomuscular o capacita a alcançar movimentos acelerados e de grandes amplitudes e pouca resistência (LIDA, 2005). A biomecânica ocupacional teme com a diferença entre a aptidão física humana e execução manual no trabalho, a interação física entre os trabalhadores e suas ferramentas, maquinas e matérias, tem como finalidade aumentar a função minimizando os riscos dos distúrbios osteomusculares (MELO, 2007).

Sintomas de distúrbios osteomusculares (SDO) tornam-se um terrível problema de saúde no trabalho, podendo ser observados em indivíduos com diversas ocupações, do setor de transporte. Estes 
sintomas acarretam alterações na efetivação das atividades cotidianas, causando afastamento do trabalho com consequências financeiras, devido á indenização de trabalhadores e gastos médicos acarretando prejuízo á sociedade (CARNEIRO et al. 2007).

Os distúrbios musculoesqueléticos despertam atenção de pesquisadores atentados à questões referente ao bem-estar e ao trabalho devido ao gasto e ao choque na qualidade de vida, causando várias doenças articulares, malefícios à coluna, distúrbios em tecidos moles, ósseos e trauma que dificulta a avaliação clínica (CARVALHO et al., 2006).

Ultimamente, os sintomas osteomusculares referente ao trabalho abrangem diversas categorias profissionais tendo estas várias qualificações, dentre elas, lesões por esforços repetitivos (LER) e distúrbios osteomusculares relacionados ao trabalho (DORT), aceitos pelos ministérios da Saúde e da Previdência Social (PICOLOTO e SILVEIRA, 2007).

O DORT (distúrbio osteomuscular relacionado ao trabalho) é de consequência multifatorial, é importante analisar os fatores de risco do trabalho envolvidos diretamente ou indiretamente. Toda essa sistemática podem ser relacionados com a adequação ao de posto de trabalho; frio, vibrações e as pressões locais sobre os tecidos; posturas impróprias; posição estática; e fatores psicossociais precedido do trabalho (BACHIEGA, 2009).

O Instituto Nacional de Seguridade Social (INSS) usa a expressão LER/DORT para constituir o conceito da síndrome, afirmando que elas não são exclusivas de movimentos repetitivos, podendo ocorrer pelo tempo prolongado dos segmentos corporais. Nesse contexto a atenção do trabalho para realização das atividades, a pressão imposta pela organização do trabalho são itens que interferem expressivamente para o desenvolvimento da síndrome (AUGUSTO et al., 2008).

De acordo com os dados da Organização Mundial de Saúde - OMS, a saúde pode ser afetada por fatores de risco como: ruído, temperatura, mobiliário, iluminação entre outros tais como: sedentarismo, ausência de comunicação, monotonia e sobretudo carência de desafios intelectuais. De acordo com esta afirmação, a saúde é a resultante do ambiente físico e emocional, agrupados a hábitos e estilos de vida (MORAIS, 2002).

O objetivo do presente estudo foi verificar a prevalência de distúrbios osteomusculares relacionados ao trabalho em cobradores de uma empresa de ônibus coletivo da cidade de Juazeiro do Norte-CE. Para isso foi necessário também: a) Quantificar as horas de trabalho por dia, quantidade de turnos e há quantos anos os profissionais exercem a atividade; b) Identificar os distúrbios osteomusculares dos profissionais nos últimos 12 meses e últimos 7 dias; c) Verificar as possíveis interferências dos distúrbios na atividade profissional dos cobradores; d) Identificar, dentre os segmentos corporais, os que mais apresentam distúrbios; e, e) Analisar a intensidade do quadro álgico dos cobradores em relação aos segmentos corporais acometidos. 


\section{Referencial Teórico}

\section{Transportes Coletivos}

Será abordado neste capitulo inicial, o surgimento da categoria de transporte coletivo e como a mesma evoluiu até os dias de hoje, conheceremos a atuação desta modalidade no Brasil, especificamente, na cidade de Juazeiro do Norte - CE.

Antigamente para se deslocar de um lugar para outro era um caos. No decorrer da evolução industrial, foram surgindo novos avanços, novas ideias, surgindo assim necessidade de criarem meios de transporte para conduzir pessoas.

Dentro deste contexto, tiveram a criação de vários meios de transporte, sendo eles aéreos, aquáticos e terrestres, com finalidade de transportar cargas, animais e pessoas. Entrando em destaque o ônibus, transporte coletivo, que serve para transportar pessoas de lugar a lugar, dentro da cidade. Temos como pessoas duas categorias importantes, neste tipo de veiculo, o motorista que conduz a maquina e o cobrador de ônibus que tem como função controlar a entrada de passageiros e receber dos mesmos o valor de cada viagem.

\section{Como Surgiram Os Transportes Coletivos}

No mês de março de 1856, o decreto $\mathrm{N}^{\circ} 1.733$ autoriza a primeira concessão de transportes urbanos que se locomovem por meio de animais sobre trilhos de ferro do Rio de Janeiro, porém em 1867 consagrava-se a estrada de ferro de Santos - Jundiaí e, a 09 de outubro, inaugurava-se a primeira linha de bonde no Brasil -puxada por tração animal e, durante os anos de 1867 a 1885 formando novas linhas férreas no país (LEMOS, 2004).

“[...] Quanto ao significado de transporte coletivo urbano, embora não tenhamos encontrado uma definição legal específica para o termo, sua definição operacional abrange o transporte publico não individual, realizados em áreas urbanas, com características de deslocamento diário dos cidadãos (BORGES, 2006 p. 4)”. [...]

Com o crescimento da urbanização nas cidades brasileiras, a capacidade de se locomover das pessoas foi se tornando cada vez mais uma batalha, devido à falta de recursos. No entanto, para facilitar o acesso das pessoas a chegarem a seu lugar de destino houve a implantação de mais transportes coletivos urbanos e com isso gerou-se mais empregos na área de motorista e cobradores de ônibus. 
Com a urbanização, houve o aumento das cidades, a população em geral precisando do transporte coletivo pra se deslocar e estabelecer suas obrigações como trabalho, estudo, saúde e lazer. (TAVARES, 2010).

O transporte coletivo é de suma importância no conjunto do transporte urbano, é essencial para a população de baixa renda e, como também, uma importante alternativa que serve para redução das viagens por automóvel, colaborando para a diminuição dos engarrafamentos, da poluição, acidentes de transito e consumo de combustível (RODRIGUES, 2008).

Segundo Ferraz (1998), o transporte coletivo é importante nas cidades pois exerce um papel social e econômico, facilitando a locomoção das pessoas, estabelece um modo de transporte reduzindo congestionamentos, poluição e o uso de energia automotiva; diminuindo a necessidade de construção de vias e estacionamentos. (CARDOSO, 2008).

O transporte coletivo oferecera um grande marco na história do Brasil, em se tratando de oferecer ao homem facilidade de se deslocar de um lugar para o outro, para isso foi necessário à implantação de pessoas sendo elas o motorista e o cobrador. Com este tipo de transporte veio a concretização de um meio que ofereceu às pessoas a possibilidade de um deslocamento rápido e seguro dentro da cidade.

Trata-se pois de um trabalho de suma responsabilidade para estes profissionais transportar pessoas, uma vez que implica desenvolver doenças relacionadas ao trabalho. Serão abordadas, no decorrer deste estudo, as alterações musculoesqueléticas que os cobradores de ônibus sofrem no decorrer de sua longa jornada de trabalho e os riscos que uma mobília mal adaptada para os mesmos pode causar.

\section{Anatomia e Biomecânica da Coluna Vertebral}

\section{Coluna vertebral e suas curvaturas fisiológicas}

A coluna vertebral forma o centro do corpo de modo a fornecer resistência de um pilar de sustentação, mas também a flexibilidade necessária à movimentação do tronco. Protegendo a medula espinhal, servindo de pivô para suporte e mobilidade da cabeça, consentindo movimentos entre as diversas partes do corpo e dá fixação a numerosos músculos (DANGELO E FATTINE, 2007).

Observa-se na figura 01, a nossa coluna vertebral, dividida em cinco partes; sete vertebras cervicais; doze torácicas, das quais dão origem as costelas; cinco lombares e cinco vertebras fundidas que formam o sacro, o qual articula-se com os ossos ilíacos da pelve; e três a cinco vertebras fundidas que originam o cóccix (KONIN, 2006). 


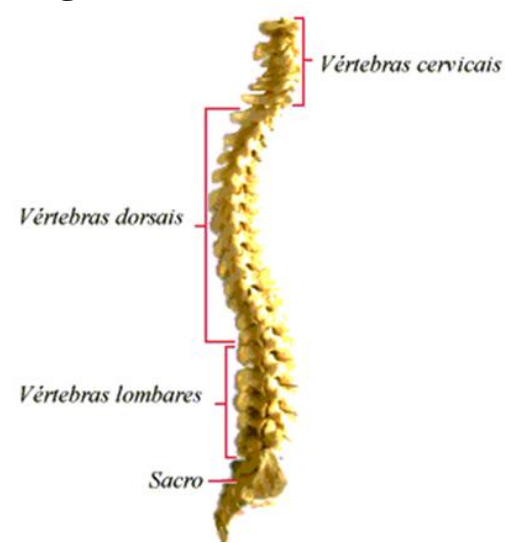

Fonte: http://www.webciencia.com/11_24tronco.htm>

A coluna humana comparada à coluna de blocos. A mesma não é completamente reta, possui uma série de curvaturas ântero-posteriores. Estas curvas precisam ser mantidas durante o repouso e a atividade, absorvendo choque que diminuem a quantidade de lesões (LIPPERT, 2003).

Entretanto a coluna vertebral possui curvaturas, sendo que as curvas torácica e sacral são contrarias às curvas cervical e lombar. Mostrando que a torácica e sacral são côncavas, anteriormente, e convexa, posteriormente, vendo que as curvas lombar e cervical são convexas, anteriormente, e côncavas, posteriormente (LIPPERT, 2003). São curvaturas fisiológicas denominadas lordose cervical, cifose torácica, lordose lombar e cifose sacral, vista na figura 02 .

\section{Figura 02 - Curvaturas da coluna vertebral}

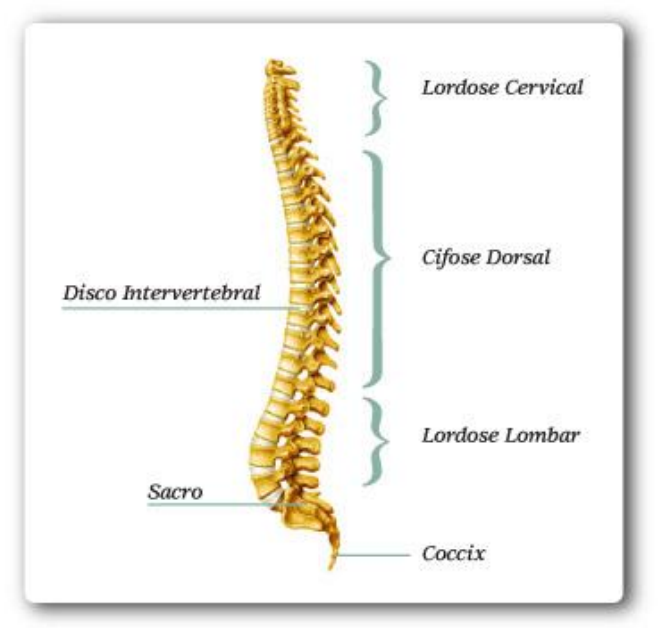

Fonte:http://quiropraxiajasongilbert.blogspot.com.br/2011/10/boa-postura-e-as-curvas-normaisda.html

O cobrador de ônibus passa longo período realizando seu trabalho sentado, e no entanto, essas curvaturas fisiológicas sofrem modificações como um todo, merecendo atenção sobre elas, pois implica dizer que futuramente causarão problemas posturais, levando a doenças osteomusculares. 


\section{Anatomia da vértebra e do disco intervertebral}

Segundo Mark, (2010), sendo a vertebra, estrutura fundamental da coluna, funciona como sustentação de peso da coluna vertebral. Apesar de sólida, fornece resistência suficiente ao corpo vertebral, para suportar cargas estáticas, é muito pesada e não tem a flexibilidade imprescindível para a manutenção de cargas dinâmicas. Podendo ser vista na figura abaixo.

\section{Figura 03 - Anatomia da Vértebra}

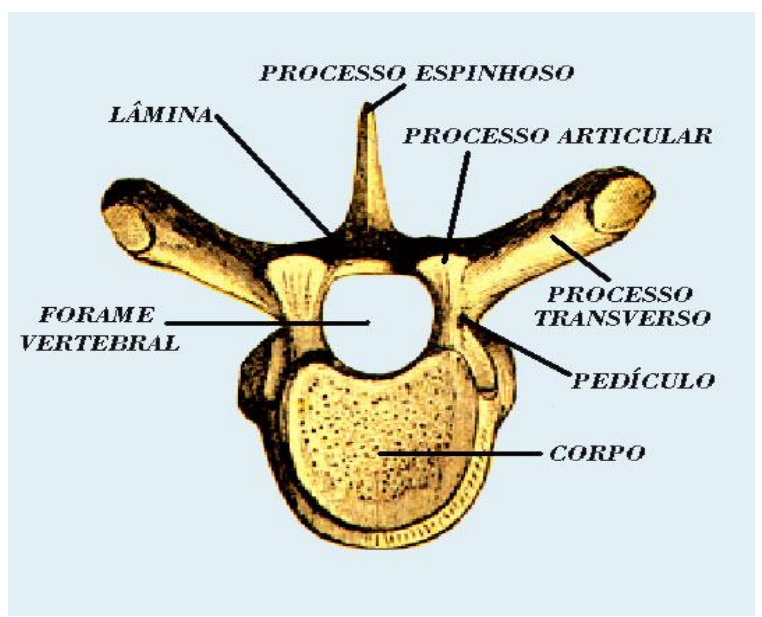

Fonte: 〈http://www.herniadedisco.com.br/doencas-da-coluna/anatomia-da-coluna-vertebral>

Para Dangelo e Fattine (2006), as vertebras articulam-se umas com as outras, conferindo rigidez, flexibilidade, qualidades necessárias para o suporte do peso, para a movimentação do tronco, para o equilíbrio e a postura. As articulações entre as vertebras são formadas no nível dos corpos vertebrais, estando entre eles o disco intervertebral, e entre os processos articulares dos arcos vertebrais.

Konin, (2006), ressalta que, o movimento realizado pelo segmento corporal móvel ocorre nas articulações através dos processos articulares e o disco intervertebral. Sendo que o disco intervertebral tem duas funções primordiais: permite discreto movimento entre os corpos vertebrais e comunicar-se de uma vertebra para outra. Ilustrada na figura abaixo a anatomia da articulação intervertebral. 


\section{Figura 04 - Articulações intervertebrais e interapofisárias.}

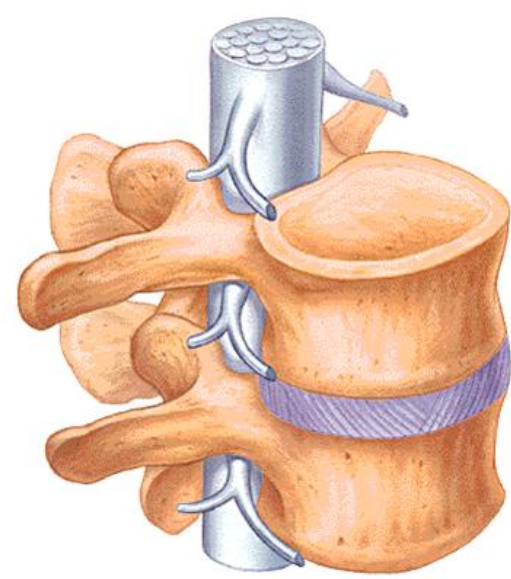

Fonte:<http://www.fm.usp.br/fofito/fisio/pessoal/isabel/biomecanicaonline/articulacoes/coluna.php>

Podemos ver a figura acima que mostra a articulação intervertebral. Os discos intervertebrais estão situados entre corpos das vértebras, originando união, alinhamento e mobilidade nas vertebras vizinhas. São como borrachas compressíveis de fibrocartilagem que ajudam a conter as forças de tração muscular, gravidade e carga que, se não estivessem ali presente, poderiam esmagar uma vertebra contra outra. O disco apresenta duas partes, sendo elas uma periférica, o anel fibroso, constituído por anéis concêntricos, mais fibrosos que cartilaginosos, que circundam uma parte central; a outra o núcleo pulposo, que é mais cartilaginoso do que fibroso, bastante elástico para atuar absorvendo choques de compressão ao qual a coluna está sujeita (DANGELO E FATTINE, 2007).

Segundo Vieira, (2004) apud Hall, (1993) o disco intervertebral é composto por um núcleo pulposo, servindo para tolerar as forças compressivas imposta pela articulação intervertebral, o anel fibroso adequa uma pressão tensiva ao disco. Podendo ser observado na figura 05.

\section{Figura 05 - Disco intervertebral}

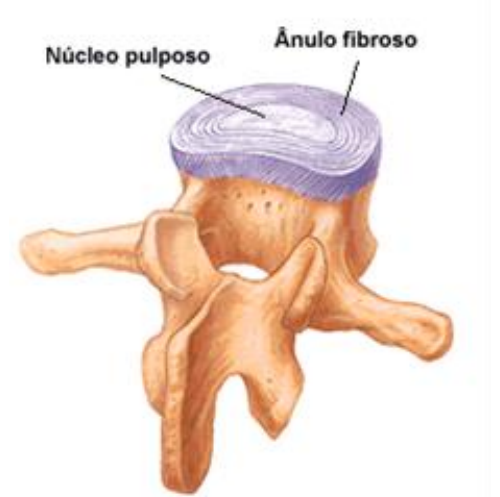

Fonte:<http://uniquephysiocare.blogspot.com.br/2011/08/coluna-vertebral.html> 
Segundo Lopes (2006), apud Kysner e Colby (1998), o disco intervertebral é uma estrutura de fibrocartilagem chamada de disco intervertebral. Sua maior parte é formada de água pelo anel fibroso que é constituído por camadas de fibrocartilagens ajudando a absorver as forças de tração muscular, gravidades e cargas estando estas entre os corpos das vértebras, o disco intervertebral é delicado e tende a envelhecer, por conta das condições mecânicas ruins tanto parado como em movimento.

Ao sentar o disco interarticular sofre compressão, havendo um deslizamento do mesmo causando compressão dos nevos que passa por aquele local, causando dor e desconforto. O disco por sua vez quando sofre uma sobrecarga, ele fica achatado e depois que essa sobrecarga é retirada volta ao seu tamanho normal, no entanto, com o passar do tempo, devido ter sofrido bastante sobrecarga, perde a capacidade de voltar a seu tamanho original. Essa compressão pode ser observada na figura 06.

\section{Figura 06 - Disco interarticular}

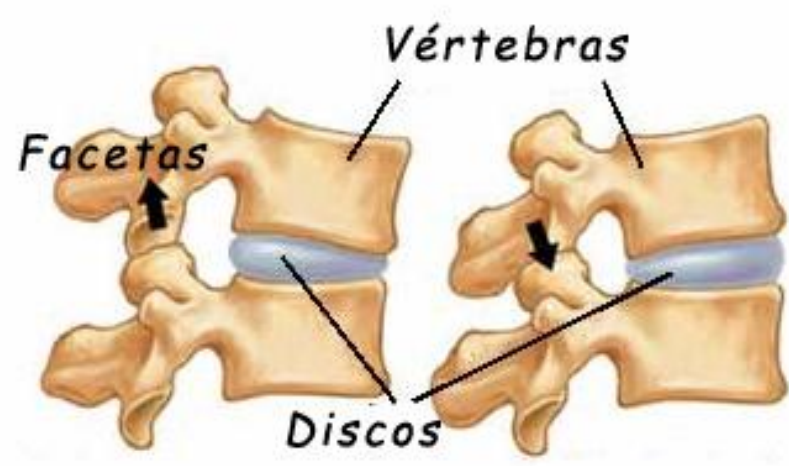

Fonte: $<$ http://www.drlucianopellegrino.com.br/website/index.php?option=com_content\&view=catego ry\&id=45\&layout=blog\&Itemid=86>

A postura incorreta ocasiona um desgaste das vértebras, dos discos e das articulações, gastando rapidamente a cartilagem articular nos pontos em que exerce maior pressão. Por causa disso, ocorrem estiramentos nos ligamentos e desestruturação muscular, porém na correta, há uma distribuição das pressões sobre os discos. Os ligamentos e os músculos irão trabalhar em conjunto evitando um desgaste antecipado das estruturas que nos aguentam (MATTOS, 2003). 


\section{Movimentos da coluna vertebral}

A coluna vertebral é um segmento complexo significativo do corpo humano. Proporcionando o elo mecânico entre as extremidades superiores e inferiores, a coluna vertebral torna possível o movimento nos três planos, porém ainda funciona como protetor ósseo da delicada medula espinhal. Para muitos pesquisadores e médicos, a região lombar da coluna tem grande interesse, sendo um dos principais problemas médicos e sócio-econômicos dos tempos modernos (HALL, 2005).

A compressão no disco tende a aumentar quando as cargas compressivas aumentam. $\mathrm{Na}$ flexão, a inclinação lateral ou a rotação, exerce uma carga compressiva fora do eixo. Fazendo com que o corpo vertebral faça o movimento de translação em para o lado que recebeu a carga, enquanto as fibras são distendidas no outro lado e a compressão do núcleo pulposo volta ao normal (VIEIRA, 2005 apud HAMILL e KNUTZEN, 2003).

No movimento de flexão da coluna, as vértebras movimentam-se para frente, empurrando o núcleo pulposo para traz, impondo uma sobrecarga na porção anterior do disco e uma carga tensiva no anel posterior. Na extensão da coluna vertebral ocorre o oposto, as vértebras superiores se movem para traz, levando o núcleo pulposo para frente e comprimindo as fibras anteriores do anel. No movimento de flexão lateral, sucede a inclinação das vertebras superiores no lado da flexão, provocando uma pressão naquele lado e tensão no lado oposto (VIEIRA, 2005 apud HAMILL e KNUTZEN, 2003).

Os movimentos limitados são possíveis entre as vertebras, pois a soma desses movimentos impõe amplitude de mobilidade na coluna. Movimentos de flexão, extensão, lateralização, rotação e circundação são todos possíveis, estabelecendo ações de maior amplitude na região cervical e lombar que no torácico. Por ventura ocorre porque os discos intervertebrais cervicais e lombares adequam maior espessura, não sofrem o efeito de contenção da caixa torácica, seus processos espinhosos são curtos e os processos articulares apresentam melhor arranjo diferente dos torácicos. No entanto a flexão é o mais articulado movimento da coluna vertebral. (NATUOR, 2004).

\section{O Cobrador e a postura sentada}

A postura sentada impõe mudanças fisiológicas na coluna lombar alterando toda estrutura musculo-esquelética da coluna vertebral. Podendo levar a adoção de má postura decorrente desta os músculos posteriores de pivô da coluna lombar cansam e relaxam. Estando esta sustentada por longo tempo irá haver o estiramento dos ligamentos e consequentemente dor. Essa postura tornando-se um hábito poderá levar a alterações nos discos intervertebrais e álgias. E quando associada a movimentos incorretos, o trabalho estático ao uso impróprio ou carência de mobiliário ergonômico. (RUMAQUELLA, et al., 2008 apud MAcKENZIE,1998). 
Em se tratando do cobrador de ônibus que realiza boa parte do seu trabalho sentado os mesmos realizam tarefas que exigem movimentos constantes de membros superiores, a contração isométrica de cadeias musculares para manter-se em uma postura que não é a fisiológica, os discos intervertebrais da coluna sofrem constante compressão levando ao desgaste, além de comprimir nervos que por aquele local passa. Sendo também exposto a vibrações do veículo que por sua vez aumenta mais ainda o desgaste articular e as dores osteomusculares. Observada na figura abaixo.

\section{Figura 07 - Postura Sentada}

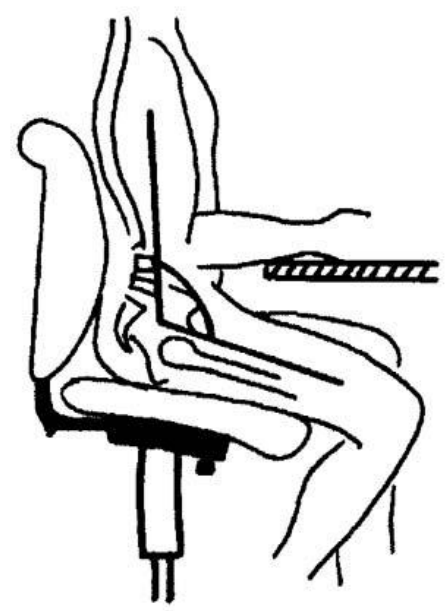

Fonte: 〈http://www.arcoweb.com.br/tecnologia/cadeiras-e-poltronas-conceitos-de-23-06-2005.html〉

Segundo Moraes (2002) apud Comparim (1998), pessoas que permanecem numa mesma posição corporal durante a jornada de trabalho, corre o risco de gerar alterações significativas no alinhamento corporal, podendo apresetar dor ou desconforto muscular. Acabam adquirindo vicios posturais, e outros problemas originários do trabalho. Porém se não forem prevenidos ou abrandados com informações sobre seu posto de trabalho e os riscos que o circundam, podem afetar a médio e longo prazo seu desempenho no dia-a-dia e na saúde e consequentemente, sua qualidade de vida. O mesmo acontece com o cobrador de ônibus, que por sua vez acaba por adotar uma postura errônea tendo que passar horas na mesma posição, levando a desenvolver problemas osteomusculares.

\section{Plexo Braquial}

O plexo braquial se trata de uma estrutura composta pela união dos ramos ventrais dos nervos cervicais inferiores (C5, C6, C7, C8), parte ventral do primeiro nervo torácico (T1) e partes do quarto nervo cervical (C4) e do segundo torácico (T2), como mostra a figura 07. As raízes C5 e C6 unem-se 
formando o tronco superior. A raiz de $\mathrm{C} 7$ origina o tronco médio. As raízes de $\mathrm{C} 8$ e de $\mathrm{T} 1$ unem-se formando o tronco inferior (PINHO, 2010).

\section{Figura 08 - Plexo Braquial}

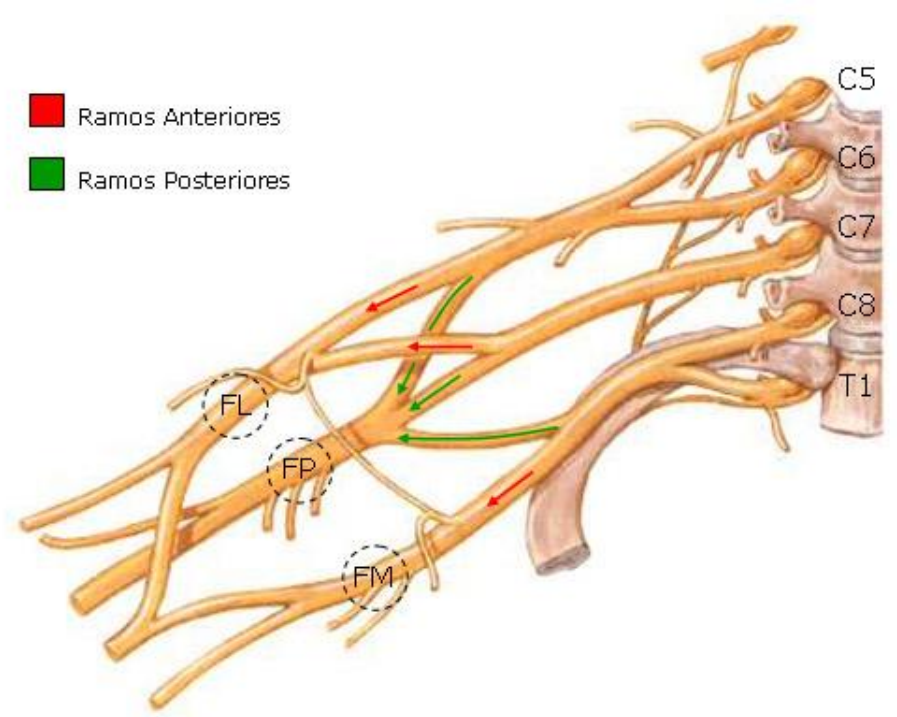

Fonte: 〈http://www.auladeanatomia.com/neurologia/braquial.htm>

São nervos que fazem ligação com o cérebro e músculos, mandando informações do cérebro para os músculos realizarem movimentos. O pensamento trafega do cérebro para a medula espinhal. Da medula espinhal passa para o plexo braquial que chega ao membro superior, sendo este responsável pelos movimentos e pela sensibilidade do membro superior (SILVA e BRAGA, 2006 apud KOUYOUMDJIAN, 1999).

Segundo Flores (2006), o plexo braquial se trata de uma estrutura complexa do sistema nervoso periférico em relação a sua exposição ao trauma. Tendo ela intima relação anatômica com estruturas moveis do pescoço e do ombro, pode ser envolvida quando os vetores de força ocasionam compressão sobre essas estruturas.

Visto acima essa estrutura tão delicada que é o plexo braquial, compõe-se de nervos que levam informações do cérebro para os membros superiores. Sendo ela, bastante acometida pelas doenças relacionadas ao trabalho, pelo fato de serem comprimidas durante a realização de movimentos repetitivos e manutenção do mesmo padrão postural por tempo prolongado, como é o caso do cobrador de ônibus, que utiliza dos membros superiores pra fazer rodar a roleta quando os passageiros entram no transporte e para administração do caixa em relação ao valor das passagens. 


\section{Plexo Lombossacral}

O plexo lombossacral, como ilustra a figura 08 , é composto pelo ramo anterior dos nervos do plexo lombar, do plexo sacral e do plexo coccígeo. Inervando as estruturas da extremidade inferior abrangendo os quadris, as nádegas e virilha e os órgãos pélvicos (BEHNKE, 2004).

\section{Figura 09 - Plexo Lombossacral}

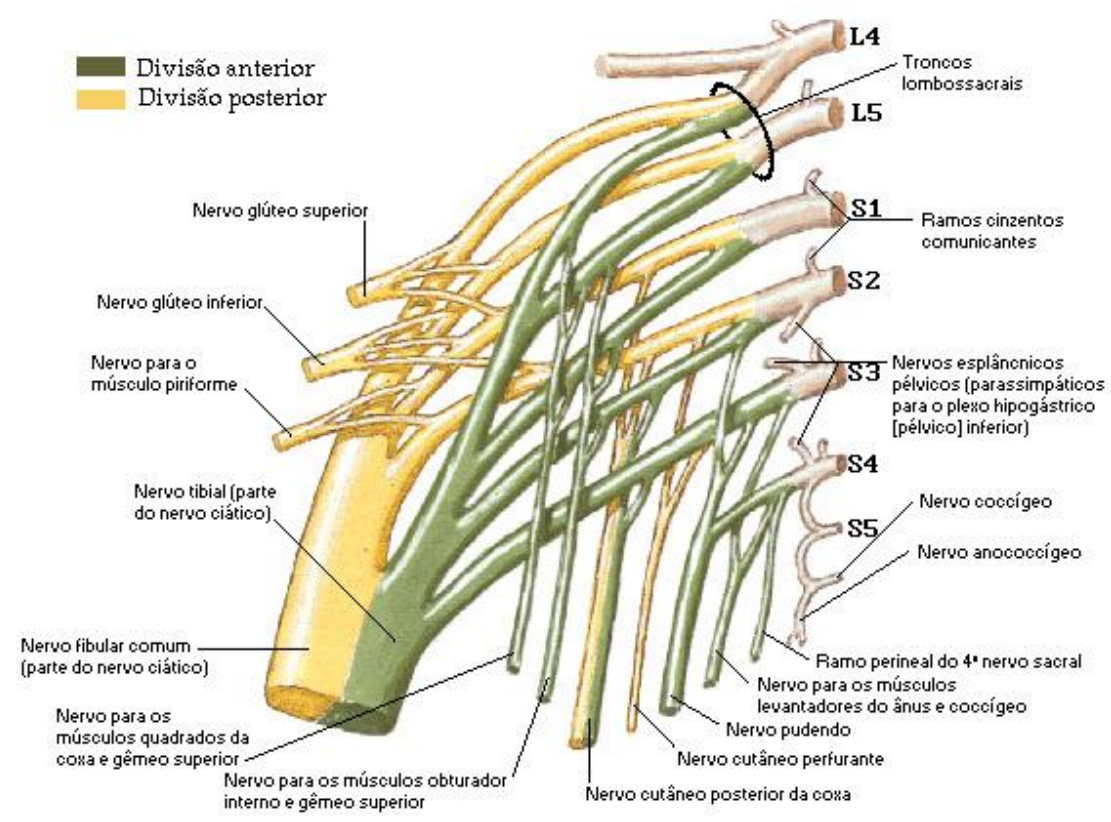

Fonte: 〈http://www.auladeanatomia.com/neurologia/sacral.htm>

A postura sentada acarreta riscos ao plexo lombossacral que é uma estrutura muito acometida de desgaste, pois nessa região passam nervos que são responsáveis por enviarem informações do cérebro para os membros inferiores. A longa permanência nesta postura provoca compressão dessas raízes nervosas trazendo dores e fadiga muscular, como é o caso do cobrador de ônibus.

Segundo Vidal (2007) apud Douglas (1997), ressalta que entre $70 \%$ a $80 \%$ boa parte da população mundial já apresentou ou ainda apresentará conhecimento em relação à dor lombar e um subgrupo destas pessoas deve essa dor ao nervo ciático.

Lombalgia significa todas as categorias de dor com ou sem rigidez, localizadas na região inferior do dorso, geralmente na linha media, na região da quarta e à quinta vértebra lombar. Pesquisas mostram que a dor está relacionada a 50\% das disfunções musculoesqueléticas sendo a mais frequente, acreditando ser a terceira causa de inabilidade para qualquer idade. (MACHADO e BIGOLIN, 2012). 
A lombalgia pode estar relacionada às compressões dos nervos lombossacrais que passam pela região L4 e L5. Podendo a mesma estar relacionada à postura sentada que por sinal é um forte indício para esse tipo de dor, gerando compressões dessas estruturas provocando um desconforto na região lombar, levando os cobradores de ônibus a desenvolverem doenças relacionadas ao trabalho.

\section{Fatores de Risco para os Cobradores de Ônibus}

Como todo ambiente de trabalho tem seus fatores de risco prejudicando em meio a vida do trabalham, causando prejuízo psíquico, orgânico, musculoesquelético e por muitas vezes, podendo afasta-lo, tornando-o inapto a realização da suas tarefas de trabalho, trazendo inúmeros prejuízos para sua vida. Serão abordados, neste capitulo, os fatores de risco, existentes no ambiente de trabalho dos cobradores de ônibus coletivo.

Os cobradores de ônibus coletivo adotam posturas incorretas que ocasionam dor e consequentemente diminuição da qualidade de vida. A tarefa de estar sentado por horas e horas é cansativa e desgastante, levando-o a inúmeros desconfortos, tais como cansaço muscular, dores articulares, estando exposto a adquirir alguma lesão. Durante a sua jornada de trabalho o cobrador de ônibus coletivo, realiza movimentos repetitivos, estando ele sentado na mesma posição. Isto associado ao transito, à poluição, leva-o a desenvolver estresse psicológico estando ele propenso a doenças osteomusculares.

A maneira como o trabalhador adota uma postura, no intuito de minimizar o desconforto postural, leva-o a ter uma sobrecarga osteomuscular, desenvolvendo dor, formigamento, câimbras e dormência. São esses ajustamentos posturais que por muitas vezes leva o individuo a ter uma alteração postural.

A adaptação de posturas incorretas no posto de trabalho junto com fatores de risco existentes mas o estresse imposto à coluna vertebral, por tempo prolongado, leva a dores que, acarretam a inatividade do individuo, diminuindo a produtividade e consequentemente afastando-o de suas atividades trabalhistas.

A postura sentada origina inúmeras alterações nas estruturais da coluna lombar. Pelo fato do individuo permanecer na postura em pé para a sentada aumenta em quase $35 \%$ a pressão interna no núcleo do disco intervertebral e todas as estruturas que ficam na parte posterior são esticadas - por ventura implica-se dizer, se o individuo estiver sentado nas melhores condições possíveis. Além dos problemas lombares, a postura sentada por longo período leva à redução da circulação de retorno dos membros inferiores, causando edema nos pés e tornozelos promovendo desconforto na região do pescoço e membros superiores (ZAPATER et. al., 2004 apud COURY, 1994). 
Segundo a Comissão de Saúde Publica da Espanha (2000), movimentos repetitivos, mantidos ao longo da jornada de trabalho, acarretam em fadiga muscular, sobrecarga, algia ou lesão. A responsabilidade do trabalho ligada a fatores psicológicos e orgânicos do trabalhador, ambiente desagradável contribuem para a formação cansaço muscular. De acordo com sua cronicidade, apresentam contraturas, a algia e a lesão. A lesão ocorre na região do ombro e dos braços, do punho e das mãos (BATTISTON et. al., 2006).

\section{Vibrações}

Vibração são movimentos oscilatórios, balanço de objetos ou qualquer movimento, que o corpo consegue fazer em um ponto fixo. É detectável com diferentes valores de aceleramento e comprometimento de onda, tendo características variáveis. Os resultados da vibração direta imposta no corpo levam a situações graves tais como, perda de equilíbrio, falta de concentração, visão turva, diminuição da visão, alteração no tecido vascular e nervoso, causando perda da habilidade manipulativa e tato das mãos. (BARBOSA, 2009).

Esses movimentos de vibração são comuns e constates em meio à jornada de trabalho dos cobradores de ônibus, muitas vezes junto com a postura que o mesmo utiliza que é a sentada, podendo causar prejuízo à coluna levado a desenvolver doenças osteomusculares.

A vibração imposta no corpo inteiro acarreta no aumento do desconforto, levando a dor, interferindo na atividade do trabalhador levando a diminuição na atuação do trabalhador (BRANDÃO et. al. 2008 apud HOY et. al. 2003).

A vibração emite reflexos musculares em função de defesa. Surgem em cada vibração, encurtando a musculatura distendida pelas vibrações. A energia vibratória é absorvida pelos tecidos e órgãos. Os músculos, são arcabouços importantes, pois a oscilação induz a contrações voluntárias e involuntárias ocasionando fadiga localizada (BRANDÃO et. al. 2008 apud CHAFFIN et. al. 2001).

As vibrações podem vir decorrentes também de fatores externos, tais como as estradas que o ônibus realiza o seu trajeto por muitas vezes não estão adequadas, e junto com o motor do veículo acentua mais ainda a vibração imposta na biomecânica corporal do individuo.

Brandão et. al., (2008) ressalta que a repetição diária das exposições á vibração no ambiente de trabalho, leva a alterações doentias das partes do corpo envolvidas. Vibrações transmitidas ao corpo podem ser qualificadas em dois tipos: vibração transmitida ao corpo inteiro ou vibração localizada atingindo um segmento do corpo. As vibrações impostas ao corpo inteiro são de baixa frequência e maior amplitude, estando na faixa de 1 a $80 \mathrm{~Hz}$, simplificadamente de 1 a $20 \mathrm{~Hz}$. As agitações verticais no sentido longitudinal da coluna adentram no corpo na posição sentado ou em pé levando inúmeras vezes ao deterioração da coluna vertebral. 
O constante aparecimento de doenças da coluna vertebral de trabalhadores que estão em frente a altas oscilações precede à hipótese de que fortes e prolongadas oscilações acarretam danos na coluna. (BRANDÃO et. al. 2008).

\section{Iluminação}

A iluminação é de suma importância e que exige atenção e precisão. Essas exigências ocasionam alterações posturais, que para estabelecer a demanda de alcançar seus objetivos o trabalhador adota posturas adaptativas. Sendo necessário estar vigilante às posturas adotadas como também às expressões faciais, pois as mesmas são indicativas da baixa iluminação. (BARBOSA, 2009).

A iluminação também se torna um enorme fator de risco na vida do trabalhador. Tendo então que tomar medidas que melhorem a realização do seu trabalho, medidas essas que não são satisfatórias, são situações que requerem uma adaptação do mesmo a medidas de iluminação, para tornar então melhor a execução da atividade.

É sabido que a iluminação artificial localizada no transporte coletivo transmite um calor que somado à iluminação natural que por sua vez também tem uma temperatura elevada, causa desconforto visual levando a ardência ocular, prejudicando a visão.

\section{Ruído}

Os ruídos acima de $90 \mathrm{~dB}$ atrapalha a comunicação verbal, forçando o aumento do tom da voz buscando chamar mais atenção dos interlocutores, causando estresse psicológico, levando a dores de cabeça. $\mathrm{O}$ abuso de ruídos interfere no desempenho das tarefas que determinam concentração mental, atenção, agilidade e exatidão dos movimentos. Causando estresse nos indivíduos, levando a contrações musculares desnecessárias, acarretando fadiga muscular. (BARBOSA, 2009).

Ruídos estão presentes em todos os lugares onde estivermos. No entanto para os funcionários que trabalham no meio de transporte coletivo urbano, como é o caso dos cobradores de ônibus, estão submetidos aos ruídos presente no veículo, como o barulho do motor e dos passageiros e também aos ruídos externos, barulho de motor de outros carros, buzinas entre outros. Isto leva o individuo a desenvolver estresse psicológico, problemas auditivo, déficit de concentração como também problemas nas cordas vocais, pois por muitas vezes sentem a necessidade de alterar a sua voz para se comunicar com outras pessoas, porque simplesmente o barulho induz a essa situação.

Segundo um estudo feito pela Comissão de Saúde Publica da Espanha (2000), o ruído se caracteriza como um som inarticulado e confuso. Para Suter (2001), o ruído é um fator de risco comum, sendo perigoso à saúde e facilmente identificado. Na maioria dos casos é viável controlar o 
excesso de ruído. Apesar disso, a ausência de programas preventivos, atenta-se o fato de que o ruído é aceito como um "mal necessário" sendo este capaz de provocar danos à saúde não é, literalmente, visível, por ventura o trabalhador seja capaz de aguentar as primeiras semanas de trabalho submetido ao ruído, tendo a sensação de já estar "acostumado" (BATTISTON et. al. 2006).

No estudo realizado por Battiston et. al.(2006) apud Ferreira e Pinto (1998), a gravidade decorrente do ruído (é preciso vários anos para provocar a surdez) e a dificuldade de colocar ligações diretas com diferentes doenças (hipertensão, estresse, aumento do número de acidentes) estabelece o ruído como um influente, mas com repercussões não tão visíveis.

O cobrador de ônibus por sua vez está submetido a esse fator de risco que são os ruídos, advindos tanto do veiculo onde trabalha e associado a ele, o barulho realizado pelos passageiros e som do rádio, são fatores que também influenciam muito, são os ruídos externos vindos das buzinas dos outros veículos. Causando estresse psicológico tencionamento muscular, fadiga mental, cefaleias tencionais entre outras.

\section{Temperatura}

Para Barbosa (2009), a percepção térmica sentida pelo corpo está determinada pela temperatura externa, umidade do ar e velocidade do vento. A temperatura é aquela que estabelece a sensação de calor e uma temperatura de ar saturado (100\% de umidade relativa) parado (sem ventos). O conforto térmico está entre as temperaturas de 20 a $24^{\circ} \mathrm{C}$ com umidade de 40 e $60 \%$ e velocidade do ar em torno de $0,2 \mathrm{~m} / \mathrm{s}$.

A temperatura é um fator bastante complexo, pois é sabido que o transporte coletivo não dispõe de áreas que ventilem todo o compartimento para que se tenha uma temperatura confortável. Que a temperatura depende do ambiente se estar frio ou quente, mas que acima de tudo também tem a umidade do ar que essa também não ajuda para que se tenha uma temperatura agradável e que adjunto com os passageiros mais a temperatura ambiental, provoca sudorese intensa e consequentemente um desconforto pelo fato de ser um ambiente fechado.

\section{Mobiliário}

De acordo com Barbosa (2009), a complexidade de manter uma postura durante o trabalho se torna razoável, se analisássemos que as amplas articulações do corpo são sinoviais, esse tipo de articulação requer nutrição para a cartilagem hialina que ocorre movimento, é necessário que se entenda que é uma postura de equilíbrio. Não podemos exigir sustentação para não forçar o individuo a realizar contrações estáticas para adquirir por tempo prolongado uma postura que, precise ser concertada a cada momento. 
O cobrador de ônibus é um funcionário que trabalha no transporte coletivo. Adotando a postura sentada no seu posto de trabalho, passa então, por longos períodos nessa mesma posição, visto que por muitas vezes o mobiliário não está adequado para o mesmo, tendo então que se ajustar a este, tornando-se então um forte candidato a sofrer alterações posturais para se manter adaptado ao seu local de trabalho.

Zapater et. al. 2004 ressalta que a maneira de diminuir as complicações oriundas da postura sentada para as estruturas músculo-esqueléticas é o planejamento ou replanejamento do espaço, com criação de uma mobília ajustável a diversas condições da tarefa e ás medidas antropométrica para cada individuo. A forma de intervenção, não é suficiente para diminuir o problema. Ideias de treinamentos preventivos são formas de minimizar sobre o organismo humano as complicações da postura sentada.

Para Reis et al. 2005, dentre as dificuldades em criar mobiliários ergonômicos é a carência de dados antropométricos da população brasileira, que geralmente não é adequado aos biótipos do nosso país (REIS et. al. 2005).

A figura abaixo mostra o mobiliário existente dentro do transporte coletivo que é ocupado pelo cobrador de ônibus, podendo visualizar a cadeira que o mesmo ocupa e a catraca onde se controla a entrada de passageiros. Visto que por muitas vezes esse compartimento não está adequado para o biótipo dos funcionários, e que na realidade também não tem medidas ajustáveis para minimizar o desconforto imposto por essa mobília.

Figura 10 - Mobiliário

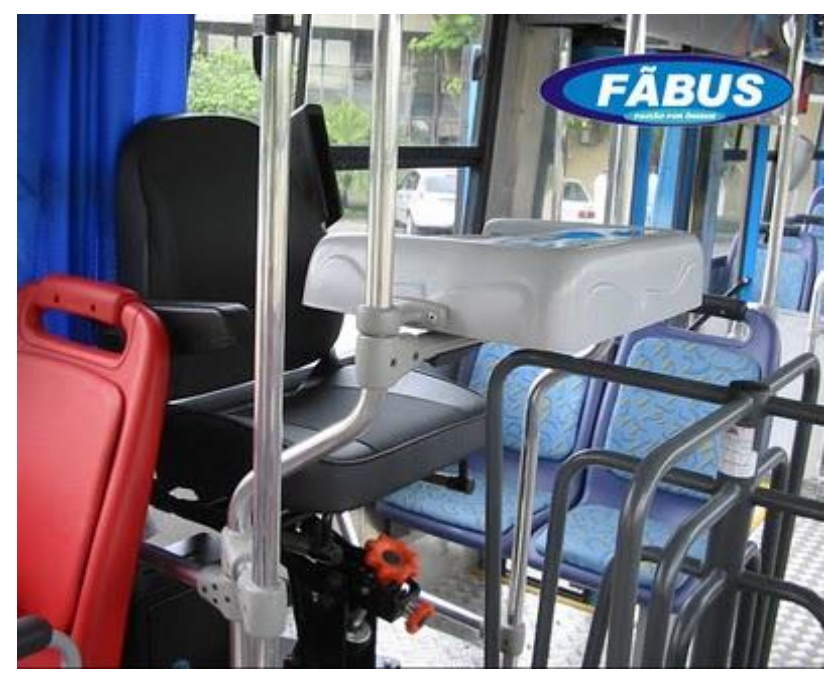

Fonte: <http://bemvivermoderno.wordpress.com/> 


\section{Fatores Organizacionais}

A missão de qualquer organização é o pleno atendimento á sociedade onde está implantada, a qualidade que se torna um fator importante para as organizações, tendo as habilidades, capacidades e conhecimentos das pessoas como ferramentas úteis á execução das tarefas, sobretudo nas organizações volvidas para a produção de serviços tendo como visão o bem-estar social. A forma como os funcionários das empresas são tratados onde trabalham, os modelos de normas e valores, os modelos de autoridade e poder vinculado a este, tudo isto influencia nas ações e nos motivos que os levam a agir (AFFONSO, 2012).

Dentro deste contexto citado pela autora acima, os fatores organizacionais de uma empresa dependem da relação funcionário e patrão junto com os demais componentes da empresa, que são os colegas de trabalho. Fatores esses que contribuem para melhor funcionamento da jornada de trabalho no dia-a-dia de cada trabalhador. No entanto, estima-se que uma boa organização é aquela que tem um bom trabalho em equipe, comunicação com os demais componentes do setor, os horários, de inicio e termino da jornada, intervalo para o almoço, horários paras reuniões entre outros, que pondo em pratica esta situação poderá abrir oportunidade para novas ideias de inovação.

No que diz respeito aos aspectos organizacionais temos a jornada prolongada, sobrecarga, acumulo de funções, demanda vocal excessiva, carência de pausas e de lugares de descanso em frente a jornada, ausência de autonomia, ritmo estressante, trabalho sob pressão e descontentamento com a remuneração (SERVILHA, et al. 2010).

Uma boa organização de trabalho em uma empresa de transporte coletivo funciona como ferramenta fundamental para que os chefes que compõem a parte administrativa, sejam responsáveis por vincular cada horário e destino de todos os ônibus ao saírem da garagem devem percorrer para que possam fornecer atendimento à população do município, tudo isso requer uma boa organização de horários, comunicação entre os dois funcionários que são de suma importância para condução da maquina que são o cobrador e o motorista. Devem dispor de uma boa parte administrativa para que não se torne cansativo nem estressante a jornada de trabalho.

\section{Fatores Psicológicos}

Os sintomas de estresse, abordado por Candeias, são suor, dor de cabeça, tensão muscular, aumento do batimento cardíaco, dores de estômago, colite e limitação. Podendo ainda se refletir em atrasos, descontentamento, sabotagem e diminuição do rendimento no trabalho, diminuição da qualidade do serviço apresentado, comprometendo a população atendida, a saúde e a qualidade de vida do trabalhador (MONTANHOLI et al. 2006). 
O estresse e suas implicações sobre a saúde humana torna-se elemento de inúmeros estudos, havendo inúmeras correntes teóricas de compressão desse fenômeno. Quanto ao estresse ocupacional procedente do ambiente de trabalho, não existe consenso quanto à sua definição entre os pesquisadores desse assunto (LIPP, 2002). O número de estresse que cada pessoa conhece pode ser modulada por fatores como experiências no trabalho, habilidade, personalidade e auto-estima (REIS et al. 2006).

\section{DORT'S}

As Lesões por Esforços Repetitivos (LER) são acontecimentos patológicos do sistema musculoesquelético, que ataca principalmente os membros superiores, ombros e pescoço, decorrentes do trabalho e de determinadas condições de trabalho. Forma um grupo heterogêneo dos distúrbios funcionais e/ou orgânicos caracterizados por episódios de vários sintomas concomitantes ou não, tais como: dor, parestesia sensação de peso e fadiga que se abrigam de forma insidiosa (CIARLINI et al., 2004).

As manifestações dos sintomas em trabalhadores trata-se de um alerta, pois mostra que o homem não se encontra doente, mas o próprio trabalho. (LONGEN, 2003 apud OLIVEIRA, 1998). Trabalhar é de fato, algo entre o homem e a natureza que está assentado pela seguinte forma: produção, distribuição, intercâmbio e consumo dos meios de vida pelos diferentes grupos humanos que implica em um processo de reprodução social (LONGEN, 2003 apud MARK, 1985).

Longen (2003) relata que, fatores que envolvem as Lesões por Esforços Repetitivos / Distúrbios Osteomusculares Relacionados ao Trabalho (LER/DORT), chama atenção nas discussões para elaborar medidas diante desse problema. Embora a atuação sobre os fatores de risco ou o destaque sobre a manifestação somática, estima-se que medidas preventivas devam conduzir melhor a ações nesta área.

Ciarlini et al. (2004), afirma em seu estudo que estes distúrbios são envolvidos por inúmeros eventos, sendo importante analisar os fatores de risco direto ou indireto. A literatura apresenta que vários são os fatores existentes no trabalho que podem contribuir para o acontecimento das LER, tais como: a repetitividade de movimentos, posturas inadequadas por tempo prolongado, o esforço físico, a inviabilidade de tarefas, a pressão mecânica sobre segmentos do corpo, o trabalho muscular estático, os choques e os impactos, a vibração, o frio e os fatores organizacionais. Visto que todos esses fatores já foram citados neste capitulo.

Geralmente as origens de LER/DORT'S estão envolvidas no trabalho e resulta da força excessiva com as mãos, posturas impróprias dos membros superiores, longa permanência em um mesmo padrão de movimento, compressão das estruturas dos membros superiores e o pouco tempo para a concretização de um trabalho, fatores psicossociais e administrativos (BURIM, 2011 apud REGIS, 1997 apud FILHO; MICHELS; SELL, 2006; TRELHA, 2004). 
As DORT'S, estão ligadas a todas a profissões que requerem o esforço, o movimento repetitivo, a longa permanência na mesma posição acarretando problemas na saúde do trabalhador. No caso do cobrador de ônibus a postura sentada os movimentos repetitivos dos membros superiores para o manuseio do dinheiro, todas as vezes que um passageiro for passar na roleta tendo o mesmo que dar suporte auxiliando nessa passagem que, no entanto já utiliza os membros superiores, tudo isso fornece indícios para o desenvolvimento de doenças osteomusculares, trazendo desconforto prejudicando a vida do trabalhador.

Domínguez et. al., (2008) apud Brito et. al., (2003), mostra que não se pode analisar apenas o tipo de postura ou discutir a existência de integração entre o tipo de trabalho e a dor na coluna, em vista que a etiologia das dores da coluna vertebral são constituídas de muitos fatores, expondo que múltiplos aspectos contribuem para isto.

As lombalgias são dores agudas ou crônicas. Estando nos distúrbios que mais agridem os seres humanos, perdem apenas para cefaléia, apresentando incidência igual nos homens e mulheres. A lombalgia, na verdade é um sintoma. Consiste em enumeradas causas; no entanto apresenta dificuldade em identificar qual a estrutura da coluna é responsável. Estruturas que devemos investigar, os discos intervertebrais, ligamentos articulações ou outras partes (VIDAL, 2007 apud GOLDENBERG, 2006).

A dor lombar referida pelos indivíduos que ficam períodos prolongados na posição sentada, podendo estar ela associada ao sedentarismo (TOSCANO E EGYPTO, 2001) á má postura, tende a gerar desequilíbrios musculares, os quais remetem novamente a má postura e um ciclo vicioso, é constituído. (CANDOTTI et. al., 2010). Ou seja, a atividade do cobrador de ônibus por sua vez tem como postura de trabalho a posição sentada, que por sinal traz inúmeros malefícios à coluna levando o individuo a desenvolver doenças relacionadas ao trabalho. E por ter essa postura acaba ao termino da jornada de trabalho adotando posturas errôneas para tentar compensar o desconforto que a outra já lhe fornecera.

\section{Metodologia}

A pesquisa realizada será de caráter observacional e de abordagem quantitativo-descritivo, implica-se dizer que será por meio da aplicação de um questionário, contendo perguntas e que o entrevistado irá responder e através das respostas, e por meio desta será realizado a tabulação dos dados que poderá então verificar a prevalência das doenças osteomusculares relacionadas ao trabalho em cobradores de ônibus coletivo.

Segundo Lakatos e Marconi (2005) retrata que o estudo Quantitativo-Descritivo - tem como base investigações de pesquisa empírica com finalidade, o delineamento ou análise das características 
de fatos ou fenômenos, a avaliação de programas. Um desses estudos utiliza-se de métodos formais, aproximando-se dos projetos experimentais, caracterizados pelo controle estatísticos, com objetivo fornecer dados para a verificação de hipóteses. Consiste na aplicação de artifícios quantitativos cujo objetivo é a coleta sistemática de dados sobre as populações, programas, ou amostras de populações e programas. Dispõe de técnicas tais como entrevistas, questionários, formulários etc. e aplicam procedimentos de amostragem.

Foi realizada em uma Empresa de Ônibus Coletivo, localizada na cidade de Juazeiro do Norte - CE. O estudo teve duração de um mês, sendo está realizada entre os dias 17 a 29 de setembro de 2012. A amostra envolveu 30 funcionários com atividades na empresa, contratados na função de cobrador de ônibus. Os profissionais foram convidados a participar da pesquisa por amostragem e adesão. Participarão aqueles que assinaram o Termo de Consentimento Livre e Esclarecido (APÊNDICE A). O critério de inclusão envolveu indivíduos do sexo masculino que trabalhavam como cobradores de ônibus há mais de um ano na referida empresa e que tinham idade a partir de 18 anos.

\section{Instrumento de Coleta de Dados}

No desenvolver da pesquisa de campo foi utilizado o Questionário Nórdico de Sintomas Osteomusculares (QNSO), versão adaptada por Serranheira et al. (2003) (ANEXO A). O questionário consta de dados, como idade, peso, altura, tempo de profissão, horas de trabalho, instrumento que utilizava para a prática de trabalho. Avaliava também sintomas álgicos tais como desconfortos e fadigas durante os últimos doze meses, sendo este item enumerado quanto a intensidade da dor nos valores de um a quatro (um: leve; dois: moderado; três: intensa e quatro: insuportável), últimos sete dias investigando se referiu dor nesse período, tendo apenas que responder sim ou não no segmento acometido. O outro item é, se durante os doze meses, algum funcionário referiu desconforto que interferisse, levando-o a ausentar-se da jornada de trabalho, tendo também que responder sim ou não no segmento acometido. Os segmentos que o questionário abordava tanto para últimos doze meses, sete dias e durante um ano eram: pescoço, ombros, cotovelos, punhos/mãos, coluna lombar, coluna dorsal, ancas/coxas, pernas/joelhos e tornozelos.

\section{Procedimentos de Coleta de Dados}

Foi realizada uma visita à empresa, onde foi constituído contato com o responsável técnico informando acerca da pesquisa, e solicitando autorização para realizá-la através de um ofício remetido 
pela coordenação do curso de Fisioterapia da Faculdade Leão Sampaio (APÊNDICE B), estando assim de acordo com a realização da pesquisa.

A coleta de dados foi realizada pela acadêmica de Fisioterapia no período de 17 à 29 de setembro de 2012, constando de visitas ao terminal de ônibus no horário de almoço 12:00 às 13:00, sendo então realizado uma pequena explanação do que se tratava a pesquisa e em seguida aplicação do questionário (ANEXO A).

\section{Análise Estatística}

Os dados foram analisados através do programa estatístico SPSS 16.0, licenciado pelo Instituto Federal de Ciência e Tecnologia do Ceará - Campus Juazeiro do Norte; para a confecção das tabelas foi utilizado o software Microssoft Excel 2010. Os resultados foram apresentados por meio de tabelas e gráficos.

\section{Resultados e Discussões}

A população estudada compõe-se de 30 cobradores de ônibus coletivo de uma empresa privada, a coleta de dados ocorreu durante o mês de setembro de 2012. O presente estudo foi composto por 30 indivíduos que tinha como função a de cobrador de ônibus, a idade variava de 21 a 58 anos, com média de 36,37 .

Tabela 1: Medidas de tendências central e de dispersão para as variáveis antropométricas, idade e ao tempo de trabalho

\begin{tabular}{ccccc}
\hline & Mínimo & Máximo & Média & DP \\
\hline Idade & 21,00 & 58,00 & 36,37 & 10,38 \\
Anos de trabalho & 1,00 & 30,00 & 6,70 & 6,72 \\
Horas de trabalho/dia & 48,00 & 72,00 & 60,20 & 9,39 \\
Peso & 50,00 & 113,00 & 77,60 & 12,91 \\
Altura & 1,20 & 1,84 & 1,67 & 0,11 \\
IMC & 19,96 & 40,04 & 27,97 & 4,26 \\
\hline
\end{tabular}

Fonte: (VIEIRA, 2012)

Pode-se ver na tabela 1 que foi possível calcular o Índice de Massa Corpórea (IMC) desses profissionais, visto que a média para o IMC foi de 27.97 esse valor indica que há um sobrepeso nesses profissionais de acordo com a OMS. 
No estudo de Rodrigues e Philippi (2008), realizado com executivos, mostrou o excesso de peso $\left(\right.$ IMC médio $=26,1 \mathrm{~kg} / \mathrm{m}^{2}$ ), nesses profissionais ressaltando que mais da metade encontrava-se com o IMC acima do padrão da normalidade. O excesso de peso traz malefícios ao individuo podendo associar a doenças cardíacas e musculoesqueléticas.

No estudo realizado por Bachiega (2006) apud João e Kussuki (2005) e Pinto et al. (2001), afirma que o aumento de massa corporal implica em danos no sistema osteoarticular gerando alterações biomecânicas na coluna e extremidades inferiores, tornando-se um fator de risco para alterações posturais e doenças associadas.

Em relação à prática de trabalho (tabela 1), a média para anos de trabalho foi de 6,70 sendo que para horas de trabalho o valor foi bem maior uma média de 60,20 mostrando uma grande diferença. Implica-se dizer que o ritmo de trabalho (horas por semana) acelerado pode afetar a saúde do trabalhador implicando uma sobrecarga de tensão, cansaço, fadiga, estresse e consequentemente levando-o a desenvolver alterações musculoesqueléticas.

Segundo Brandão (2005), afirma que o intenso ritmo de trabalho se torna um amplo fator de risco para a obtenção de distúrbios osteomusculares.

O estudo de Moreira e Mendes (2005), realizado com uma equipe de Enfermagem, aborda o ritmo de trabalho dizendo que os profissionais de enfermagem que trabalhavam em ritmo rápido $(65,12 \%)$ estavam predispostos a uma sobrecarga de trabalho, ou seja, é relevante quando se tem uma carga horária de trabalho bastante intensa pode desencadear alterações.

A tabela 2 mostra que a maior distribuição de cobradores trabalha no turno da manhã e da tarde.

Tabela 2: Distribuição dos sujeitos quanto à quantidade de turnos, por dia, que os mesmos trabalham

\begin{tabular}{ccc}
\hline & $\mathbf{n}$ & $\boldsymbol{\%}$ \\
\hline Manhã/Tarde & 19 & 63,3 \\
Tarde/Noite & 3 & 10,0 \\
Manhã/Tarde/Noite & 8 & 26,7 \\
\hline
\end{tabular}

Fonte: (VIEIRA, 2012)

Quanto ao membro dominante utilizado durante a escrita, a tabela 3 descreve que $(n=26$; $86,7 \%$ ) desses profissionais são destros. 
Tabela 3: Distribuição dos sujeitos quanto à dominância

\begin{tabular}{ccc}
\hline & $\mathbf{n}$ & \% \\
\hline Destro & 26 & 86,7 \\
Canhoto & 1 & 3,3 \\
Ambidestro & 3 & 10,0
\end{tabular}

Fonte: (VIEIRA, 2012)

O gráfico 1 mostra a interferência do trabalho no aparecimento de algias.

Gráfico 1: Distribuição dos sujeitos quanto a prevalência de distúrbios musculoesqueléticos na coluna nos últimos 12 meses, nos últimos 7 dias, e a interferência destes na realização do trabalho nos últimos 12 meses

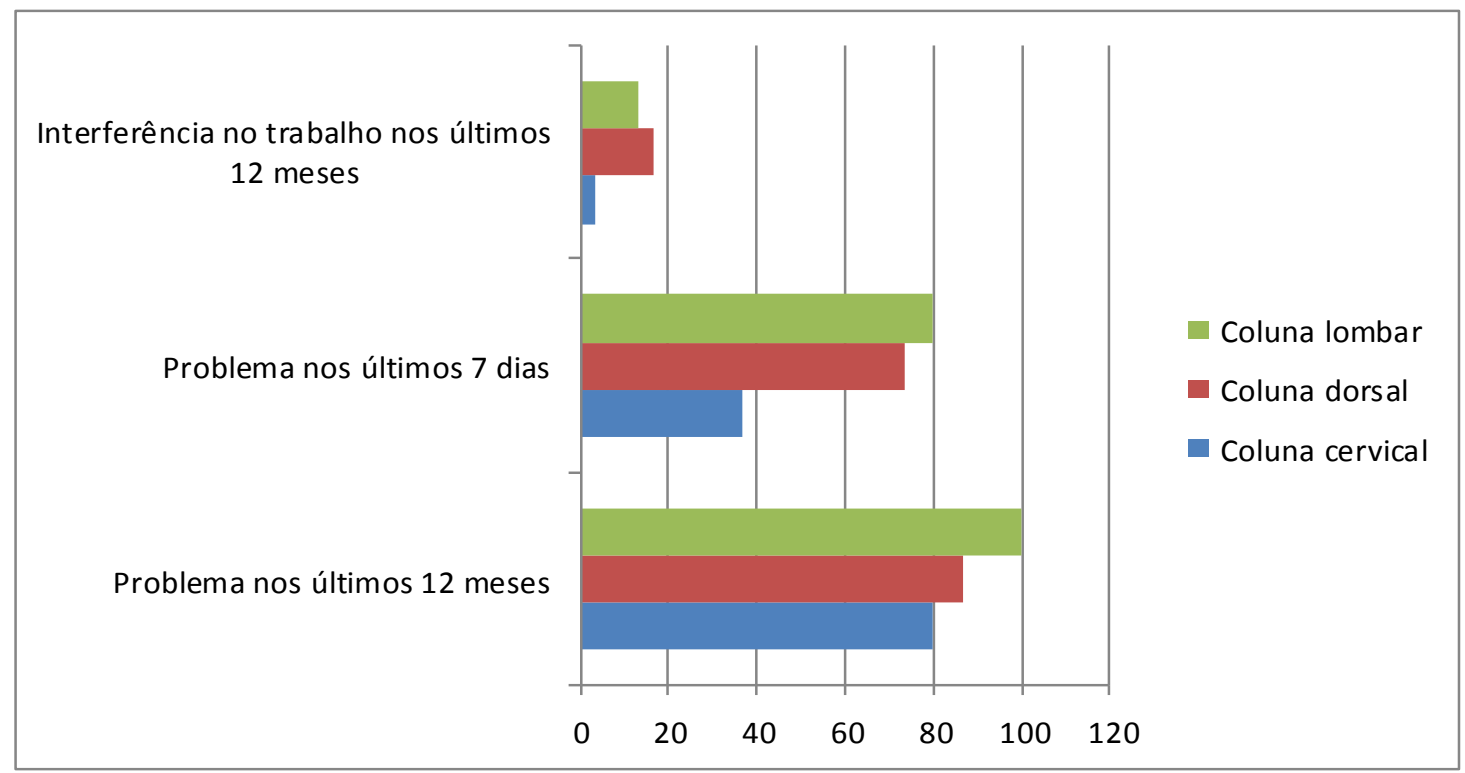

O gráfico acima mostra que todos os segmentos da coluna tiveram problemas

$100,0 \%$ dos profissionais apresentou na coluna lombar e dorsal 86,7\%. O que apresentou mais interferência no trabalho foi à região dorsal com 16,7\% comparando-se com a lombar 13,3\%. Mas pode-se concluir que todos esses segmentos da coluna são acometidos, estando em terceiro lugar a cervical, segundo lugar à torácica e em primeiro lugar a lombar região que mais sofre agressão por conta da postura sentada durante a jornada de trabalho desses profissionais.

Gurgueira et al., (2003), em seu estudo realizado com trabalhadores de Enfermagem, mostrou diferença em relação à dor lombar, que esta foi a causa mais referida para explicar a falta no trabalho e a busca de auxilio médico. Dentre os participantes, 13,3\% mencionaram ter se ausentado do trabalho devido à dor lombar, e 25,7\% procuraram um médico devido a esse problema no período de um ano. Sendo que nesse estudo a dor lombar (13,3\%) não se mostrou um fator tão referido para se faltar ao trabalho. 
O presente estudo realizado com cobradores de ônibus corroborou com o estudo de Fracon et al., (2012), em seu estudo feito com cirurgiões dentistas mostrando que posturas viciosas tais como inclinações laterais, flexões e extensões da coluna durante o trabalho estando por longos períodos sentados. Na maioria das vezes estas posições levam-no a alterações de origem postural, como as escolioses, cifoses e lordoses. É sabido que a coluna do homem não dispõe de modelo biomecânico correspondente para conservar-se por longos períodos na posição sentada, sustentando posturas estáticas fixadas agregadas a movimentos repetitivos.

Segundo Toscano e Egypto (2001) afirma que a estabilização nas estruturas que compõem a coluna vertebral, impedindo quadros dolorosos a ela relacionados, não se estabelece em tarefa fácil, sobretudo pelas constantes mudanças posturais realizadas diariamente pelo homem, exibindo sua estrutura morfológica funcional a constantes agravos.

Toscano e Egypto (2001), diz que as estruturas músculo-articulares atuam no antagonismo das ações mecânicas do segmento lombar: eixo de manutenção do corpo e eixo de movimentação. Carência ou aumento de esforço físico nesses segmentos acarretará danos á mecânica do ser humano em seus componentes osteomusculares e articulares.

Um estudo semelhante a este com cobradores de ônibus, realizado por Carneiro et al. (2007), utilizando o questionário nórdico, aplicado a motorista e cobradores de ônibus, mostrou que a ausência no trabalho nos últimos doze meses, se fez mais frequente em cobradores $(33,3 \%$ e $23,7 \%)$ do que em motoristas $(26,6 \%$ e $21,8 \%)$.

No estudo realizado por Sousa (2009) com motoristas de ônibus alternativo, 28,8\% desses profissionais apresentou dores na coluna lombar, sendo esta região a que mais apresentou indicativo de afastamento em relação à coluna dorsal 16,6\%. O presente estudo se assemelha com o estudo citado acima no que diz respeito a ser uma profissão que utiliza como postura de trabalho, a sentada, porém esta pesquisa não corrobora com o estudo do autor acima, pois os cobradores de ônibus tiveram um índice de afastamento maior pelos desconfortos causados na coluna dorsal $(16,7 \%)$ em relação à coluna lombar $(13,3 \%)$.

A tabela 04 especifica a distribuição dos sujeitos quanto à prevalência dos distúrbios musculoesqueléticos. 
Tabela 04: Distribuição dos sujeitos quanto a prevalência de distúrbios musculoesqueléticos nos membros superiores nos últimos 12 meses, nos últimos 7 dias, e a interferência destes na realização do trabalho nos últimos 12 meses

\begin{tabular}{|c|c|c|c|c|c|c|}
\hline & \multicolumn{2}{|c|}{ Últimos 12 meses } & \multicolumn{2}{|c|}{ Últimos 7 dias } & \multicolumn{2}{|c|}{$\begin{array}{c}\text { Interferência do trabalho } \\
\text { nos últimos } 12 \text { meses }\end{array}$} \\
\hline \multicolumn{7}{|c|}{ Ombros } \\
\hline & $\mathbf{N}$ & $\%$ & $\mathbf{n}$ & $\%$ & $\mathbf{n}$ & $\%$ \\
\hline No direito & 2 & 6,7 & 0 & 0 & & \\
\hline No esquerdo & 0 & 0 & 0 & 0 & 1 & 3,3 \\
\hline Nos dois & 17 & 56,7 & 8 & 26,7 & & \\
\hline \multicolumn{7}{|c|}{ Cotovelos } \\
\hline & $\mathbf{N}$ & $\%$ & $\mathbf{n}$ & $\%$ & $\mathbf{n}$ & $\%$ \\
\hline No direito & 1 & 3,3 & 0 & 0 & & \\
\hline No esquerdo & 0 & 0 & 0 & 0 & 0 & 0 \\
\hline Nos dois & 4 & 13,3 & 1 & 3,3 & & \\
\hline \multicolumn{7}{|c|}{ Punhos/mãos } \\
\hline & $\mathbf{N}$ & $\%$ & $\mathbf{n}$ & $\%$ & $\mathbf{n}$ & $\%$ \\
\hline No direito & 2 & 6,7 & 1 & 3,3 & & \\
\hline No esquerdo & 2 & 6,7 & 0 & 0 & 0 & 0 \\
\hline Nos dois & 3 & 10,0 & 1 & 3,3 & & \\
\hline
\end{tabular}

Fonte: (VIEIRA, 2012)

Os resultados mais relevantes apresentados na tabela acima, quanto aos desconfortos mostrados por esses profissionais, foram nos ombros. Isso implica dizer que é uma estrutura que pode ser tensionada por conta de preocupação, fadiga e estresse no dia-a-dia levando o individuo a desenvolver algum tipo de distúrbio osteomuscular relacionado ao trabalho.

Mognago et al. (2009), afirma que sistema nervoso central quando ativo pelo estresse, aumenta a atividade de formação reticular, aumentando o tônus muscular estimulando a sobrecarga que leva ao aparecimento de DORT.

O estudo de Graça et al. (2006) apud Ferreira (1997), afirma que desalinhamentos musculoesqueléticos relacionados ao trabalho adequa-se a um grupo de afecções heterogêneas que agridem músculos, tendões, sinóvias, articulações, vasos e nervos, tornando vitimas trabalhadores submetidos a diversas condições de trabalho. Sucede-se em algum local do aparelho locomotor, embora as regiões cervical, lombar e os membros superiores são os mais envolvidos.

O gráfico 2 descreve a prevalência dos distúrbios musculoesqueléticos nos membros inferiores. 
Gráfico 2: Distribuição dos sujeitos quanto a prevalência de distúrbios musculoesqueléticos nos membros inferiores nos últimos 12 meses, nos últimos 7 dias, e a interferência destes na realização do trabalho nos últimos 12 meses

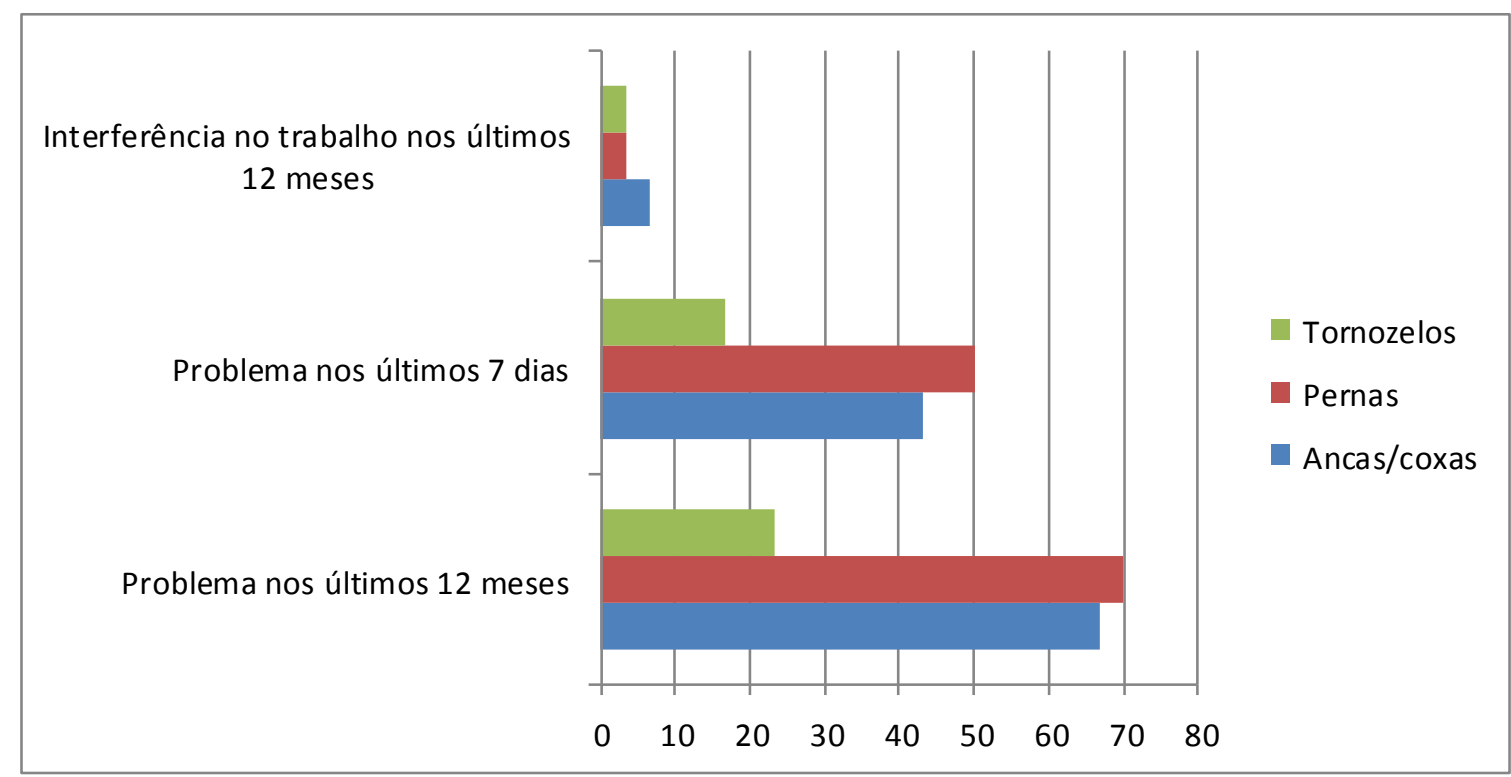

Visualiza-se no gráfico acima que todas as regiões foram acometidas por quadro álgico. Visto que esses profissionais apresentaram problemas nas pernas, não há nada que imponha sobrecarga nessa estrutura, no entanto vale salientar que, esses sintomas podem ser oriundos da má circulação, por eles passarem horas sentados, há uma diminuição do retorno venoso, causando dor, formigamento, paresia e fadiga.

Moraes (2002) apud Calliet (1988), constatou que a origem da dor se dá pela redução do aporte sanguíneo resultando em tensão muscular decorrente de uma mesma postura. As contrações mantidas por longo tempo auxiliam no acúmulo de catabólitos no tecido muscular prejudicando a irrigação intrínseca. A dor e a hiperestesia podem ocorre na massa muscular, resultando de uma contração, aguda, repetida ou constante.

Moraes (2002) apud Grandjean (1998), o trabalho ativo para este autor é o que permite contrações e relaxamento alternados dos músculos, o musculo age como uma bomba sobre o sistema circulatório, pois aumenta a circulação sanguínea beneficiando a remoção de resíduos que originam a dor, sendo mais indicado para a conservação da integridade do sistema osteomioarticular e do bemestar do trabalhador.

O que acontece com os cobradores de ônibus por manterem a postura sentada por tempo prolongado, é uma deficiência na circulação sanguínea, levando-o a desenvolver sintomas álgicos.

Esse estudo corrobora com Reis et al. (2005) afirmando que na postura sentada a circulação sanguínea altera expressivamente, e o retorno venoso até o coração se torna complicado, pois a compressão na parte posterior das coxas, se torna um obstáculo para a circulação. 
O gráfico 3 mostra o nível de intensidade de desconforto desses profissionais em todos os segmentos corporais referente ao questionário.

Gráfico 3: Classificação da dor em nível de intensidade, por segmentos, em cobradores de uma empresa de ônibus a partir dos seus valores percentuais respectivos.

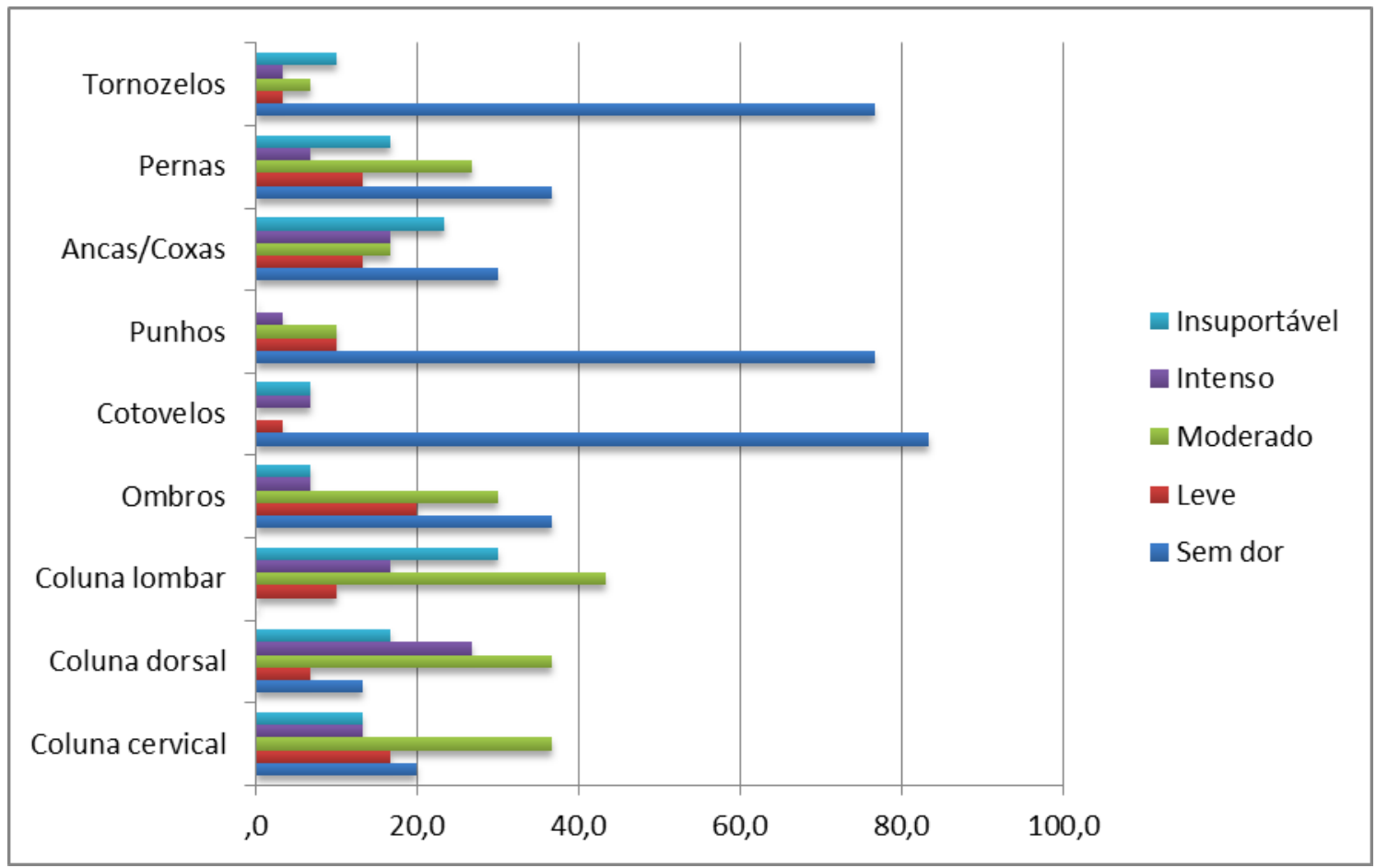

Fonte: (VIEIRA, 2012)

Visualiza-se que para coluna lombar foi zero para o quesito sem dor em ralação aos outros segmentos. Para o quesito leve obtiveram valores iguais os seguintes segmentos ancas/coxas e pernas $(13,3)$, tornozelos e cotovelos $(3,3)$ e coluna lombar e punho $(10,0)$, em relação aos outros segmentos que tiveram valores diferentes. Coluna dorsal e cervical no quesito moderado tiveram valores iguais $(36,7)$ enquanto que para as outras regiões permaneceram diferentes. Enquanto que para intenso, tornozelos e punhos tiveram valores iguais $(3,3)$. Os valores para intenso e insuportável permaneceram iguais para coluna cervical $(13,3)$, ombros e cotovelos $(6,7)$ e diferentes para os demais segmentos. Os segmentos corporais frente à postura sentada desses funcionários referiram mais dor na coluna lombar, dorsal e cervical do que em relação aos outros segmentos. Isso sugere que os funcionários sentem mais dor nos nessas regiões supracitadas, pelo fato da sua biomecânica durante a jornada de trabalho.

Visualiza-se que para coluna lombar foi zero para o quesito sem dor em ralação aos outros segmentos. Sendo que na coluna vertebral, a classificação de intenso, a torácica teve primeiro lugar estando em segundo a lombar e em terceiro a cervical. 
Os segmentos corporais frente à postura sentada desses funcionários o que referiu mais dor foi a coluna como um todo em relação aos outros segmentos. Isso sugere que os funcionários sentem mais dor nessas regiões, pelo fato da sua biomecânica durante a jornada de trabalho.

Patussi (2005), afirma que pequenos movimentos do pescoço são intensamente prejudiciais para a parte alta da coluna se tornando ainda mais critico quando a cabeça e o pescoço conservar-se em posições de flexão, inclinação lateral ou rotação.

Condotti, Noll e Cruz (2010), em seu estudo com 30 manicures, mostraram que (n=29) das profissionais referiram dor na região lombar apenas uma não referiu dor nessa região. A mesma amostra utilizada nesse estudo com $(n=30)$ cobradores de ônibus, porém todos eles apresentaram dor na região lombar.

No estudo de Carvalho e Alexandre (2005), realizado com professores, utilizando o Questionário Nórdico exibiram alta prevalência de sintomas musculoesqueléticos, nos últimos doze meses e últimos sete dias, na região lombar, torácica, cervical, ombros, punhos e mãos. Tal fato foi apresentado nesse estudo, pois essas mesmas regiões apresentaram desconfortos, porém os de menos desconforto foram cotovelos, punhos e tornozelos.

Pode-se ver que nesse estudo 36,7\% dos cobradores de ônibus apresentaram dores nas pernas, podendo ser devido a má circulação como já foi citado nos resultados do gráfico 10 , mas também pode ser advindo de compressões em nervos da coluna que irradia essa dor para as pernas causando cansaço, desconforto e fadiga.

Em um estudo realizado com mototaxistas por Morais (2010), os membros inferiores apresentaram 17,8\% das queixas, podendo ser um sinal de problemas circulatórios que pode ser oriundo da coluna dorsal, pois esta região quando acometida reflete dores nas pernas. Os problemas relatados pelos cobradores de ônibus podem estar relacionados às compressões nervosas ao nível da coluna, pois os mesmos tem em toda a jornada de trabalho a posição sentada resultando de compressões nessa estrutura que leva ao aparecimento de quadros álgicos.

Pereira e Graça (2008), afirma que as jornadas semanais semelhantes ou abaixo há 35 horas tinham maior importância de dor/desconforto nas regiões de pescoço e ombros (50\%) e nas jornadas acima de 35 horas semanais a dor foi mais referida na região lombar $(44,34 \%)$.

No estudo de Bachiega (2009) realizado com cirurgiões-dentistas com uma amostra de $n=100$, os segmentos anatômicos mais acometidos foram o pescoço (81\%), lombar (78\%), ombros (70\%), punho (67\%), região dorsal (65\%) quadris (51\%), braços (53\%), antebraço (36\%) e cotovelos (33\%). Corroborando com esse estudo em relação ao que mais apresentou acometido foi a região cervical, ombros, lombar e torácica. Pode-se observar que os sintomas musculoesqueléticos aparecem em todos os segmentos corporais, porém com certa intensidade em pontos específicos, como a coluna, que, no entanto é a mais acometida nesses profissionais por permanecerem por uma extensa carga horária na mesma postura. 
No estudo realizado com 10 funcionários de uma construtora civil por Nogueira (2011), a região que se mostrou, ser mais acometida foi a lombar $(37,03 \%)$, porém não foi o motivo de afastamento desses funcionários durante a jornada de trabalho.

A semelhança que existe nos resultados desse estudo com os estudos de Nogueira (2011), foi que toda sua amostra apresentou dores na região lombar sendo que não foi o motivo de ausência ao trabalho.

\section{Conclusão}

Os resultados encontrados mostraram que há uma grande frequência de dores osteomusculares relacionadas ao trabalho nos cobradores de ônibus. O destaque dos ponto mais referidos dor por esses profissionais foram à coluna cervical, torácica, lombar, ombros, ancas/coxas e pernas. Sendo que a mais frequente dentre estes foi a lombar o que justifica pelo fato dessa estrutura ser a mais acometida mediante a postura sentada e uma maior pressão nos discos intervertebrais.

Também se pode ver através da detalhada análise dos dados, que os sintomas musculoesqueléticos podem estar associados ao excesso de peso que foi possível verificar através da idade e altura calculando o IMC desses profissionais que mostrou uma média de 27,97, que é sabido que o excesso de peso pode trazer inúmeros malefícios não só ao coração e às outras doenças, como também à coluna vertebral sendo este também um fator que contribui para distúrbios osteomusculares acarretando em cansaço, desconforto e fadiga.

Os membros inferiores e superiores não forma mencionados como uma sintomatologia significativa em relação à toda coluna que essa foi a que mostrou sofrer agressão expressiva perante a jornada de trabalho. Sendo o fato desses profissionais não utilizarem constantemente os membros superiores para executarem suas atividades no trabalho. Nos membros inferiores, o resultado foi superior quanto à intensidade em relação aos membros superiores, o que justifica os membros inferiores terem apresentado uma sintomatologia maior é o fato da postura durante o trabalho ser sentada, esta a carreta diminuição do retorno venoso pela flexão de joelho e a compressão de nervos e discos intervertebrais acarretando dores nas pernas.

Como já era de se esperar mediante os resultados obtidos em relação à coluna lombar, esta foi pioneira em referência de dor nos profissionais cobradores de ônibus, e essa região é a que mais sofre modificações mediante a postura sentada que somada à longa jornada de trabalho resulta em um longo período na mesma posição. Podemos também levar em consideração os fatores de risco durante o trabalho como as vibrações impostas pelo transporte, estresse no dia-a-dia, mobiliário inadequado ao biótipo de cada profissional, procedendo em alterações musculoesqueléticas que levam às dores 
osteomusculares. Entretanto essa não foi a causa de afastamento do trabalho no período de doze meses.

Pode-se ver que o questionário se fez um importante instrumento avaliativo nesta pesquisa, tornando-se um valioso método investigativo, para sintomas músculos esquelético, tornando possível mostrar através deste que esses profissionais tão importantes no meio social sofrem distúrbios musculoesqueléticos.

A dificuldade em realizar esse estudo foi devido à escassez de outros estudos realizados com cobradores de ônibus, visto que estudos realizados com outros profissionais de outras àreas tinham certa diversidade, no entanto esse estudo poderá abrir campo para novos estudos na área da Ergonomia e Saúde do trabalhador, tornando-se um instrumento viável para novas linhas de pesquisa.

\section{Referencias}

AFFONSO, L. M. F.; ROCHA, H. M. Fatores organizacionais que geram insatisfação no servidor público e comprometem a qualidade dos serviços prestados. In: SIMPÓSIO DE EXCELÊNCIA E GESTÃO E TECNOLOGIA RESENDE, 7., 2010, Resende. Anais eletrônicos... Resende: AEDB, 2010. <http://www.aedb.br/seget/artigos10/234_SEGeT_Fat_Organizacionais_c_autores.pdf> Acesso em: 05 Ago. 2012.

AUGUSTO, V. G.; et al. Um olhar sobre as ler/dort no contexto clínico do fisioterapeuta. Revista Brasileira Fisioterapia. São Paulo, v. 12, n. 1, p. 49-56, 2008.

BACHIEGA, C. M. M. V. A prevalência de sobrepeso e obesidade em escolares e a influencia nas alterações posturais no aparelho locomotor. Botucatu: Universidade Estadual Paulista, 2006.

BACHIEGA, J. C. Sintomas de distúrbios osteomusculares relacionados à atividade de cirurgiões-dentistas brasileiros. São Paulo: Universidade Nove de Julho, 2009.

BARBOSA, L. G. Fisioterapia preventiva nos Distúrbios Osteomusculares Relacionados ao Trabalho - Dort's. 2 ed. Rio de Janeiro: Guanabara Koogan, 2009.

BATTISTON, M.; CRUZ, R. M.; HOFFMANN, M. H. Condições de trabalho e saúde de motoristas de transporte coletivo urbano. Estudos de Psicologia. Florianópolis, v.11, n. 3, p. 333-343, 2006.

BEHNKE, R. S. Anatomia do Movimento. Porto Alegre: Artmed, 2004.

BORGES, R. C. N. Definição de transporte coletivo e urbano, biblioteca digital da câmera dos deputados consultoria legislativa. Distrito Federal, Brasília: Biblioteca Digital Câmara dos Deputados, $2006 . \quad$ Disponível em: <http://bd.camara.gov.br/bd/bitstream/handle/bdcamara/1720/definicao_transporte_borges.pdf?sequen ce $=1>$. Acesso em: 09 mar. 2012.

BRANDÃO, J. G. T., TOMAZINE, J.E, AMANN, B. O. Análise de vibrações em assentos de empilhadeira. In: BRAZILLIAN CONFERENCE ON DYNAMICS, CONTROL AND 
APPLICATIONS DINCON, 7., 2008, São Paulo. Anais eletrônicos... São Paulo: UNESP, 2008. Disponível em: <http://www4.fct.unesp.br/dmec/dincon2008/artigos/05/01-05Brando\%5B1\%5D.doc.pdf>. Acesso em: 12 out. 2011.

BRASIL. Resolução CNS $\mathrm{n}^{\circ}$ 196, de 10 de outubro de 1996. Aprova diretrizes e normas regulamentadoras de pesquisa envolvendo seres humanos. Diário Oficial da União, Brasília, n. 201, p. 21082,16 de out. 1996. Seção 1.

BURIM et. al. Presença de LER/DORT'S em um grupo de bancários da cidade de Erechim - RS. Perspectiva. Erechim, v. 35, n. 129, p. 93-120, mar. 2011. Disponível em: <http://www.uricer.edu.br/new/site/pdfs/perspectiva/129_157.pdf>. Acesso em: 24 abr. 2012.

CANDOTTI et al. Prevalência de dor lombar e os desequilíbrios musculares em manicures. Rev. Eletrônica da Escola de Educação Física e Desportos - UFRJ. [online]. Rio de Janeiro, v. 6, n. 1, p. 93-102. Jan./Jun. 2010. Disponível em: <http://vomer2.eefd.ufrj.br/ revista/index.php/EEFD/article/view/94/96>. Acesso em: 12 ago. 2012.

CARDOSO, C. E. P. Análise do transporte coletivo urbano sob a ótica dos riscos e carências sociais. São Paulo: Universidade Católica de São Paulo PUC, 2007.

CARNEIRO, L. R.V. et al. Sintomas de distúrbios osteomusculares em motoristas e cobradores de ônibus. Revista Brasileira Cineantropometria e Desempenho Humano [online]. Florianópolis, v. 9, n.3, p. 277-283, 2007.

CARVALHO, A. J. F. P. e ALEXANDRE, N. M. C. Sintomas osteomusculares em professores do ensino fundamental. Revista Brasileira Fisioterapia. São Paulo, v. 10, n. 1, p. 35-41. 2006.

CARVALHO, A. J. F. P. e ALEXANDRE, N. M. C. Sintomas osteomusculares em professores do ensino fundamental. Revista Brasileira Fisioterapia. São Paulo, v. 10, n. 1, 2006.

CIARLINI, et. al. Lesões por esforço repetitivo em fisioterapeuta. Revista Brasileira em Promoção da Saúde. Fortaleza, v. 18, n. 1, p. 11-16, 2005. Disponível em: <redalyc.uaemex.mx/.../ForazarDescargaArchivo.jsp?> Acesso em: 09 ago. 2012.

DANGElO, J. G.; FATINE, C. A. Anatomia humana sistêmica e segmentar. 3 ed. São Paulo: Editora Atheneu, 2007.

DELIBERATO, P. C. P. Fisioterapia preventiva: fundamentos e aplicações. Barueri, SP: Manole, 2002.

DOMínGUEZ, A. G. D. et al, Prevalência de lombalgia em acadêmicos e funcionários do centro universitário UNIERO. Habilitar. Brasília, v. 11, n. 2, abr./set. 2008. Disponível em: <http://www.unieuro.edu.br/downloads_2005/fisioterapia/revista_habilitar_02_prevalencia.pdf>. Acesso em: 12 ago. 2012.

FLORES, L. P. Estudo epidemiológico das lesões traumáticas de plexo braquial em adultos. Arquivos Neuro-Psiquiatra. São Paulo, v. 64, n. 1, p. 88-94, 2006. Disponível em: <http://www.scielo.br/pdf/anp/v64n1/a18v64n1.pdf>. Acesso em: 12 set. 2012

FRANCON, J. F. et al. Estudos epidemiológicos de sintomas osteomusculares em cirurgiões-dentistas do Distrito Federal. Revista Movimenta. Goiânia, v. 5, n. 1, 2012.

GRAÇA, C. C. et al. Desordens musculoesqueléticas em cirurgiões-dentistas. Sitientibus. Feira de Santana, n. 34, p. 71-86, jan./jun. 2006. 
GURGUEIRA, G. P. et al. Prevalência de sintomas músculo-esqueléticos em trabalhadores de enfermagem. Revista Latino-americana Enfermagem. São Paulo, v. 11, n. 5, p. 608-613; set./out., 2003.

HALL, S. J. Biomecânica básica. 4 ed. Rio de Janeiro: Editora Guanabara Koogan, 2005.

KONIN, J. Cinesiologia: prática para fisioterapeutas. Rio de Janeiro: Guanabara Kooga. 2006.

LEMOS, G. de S. F., Transporte coletivo em goiânia: um estudo das representações sociais. Goiás: Universidade Católica de Goiás, 2004.

LIPPERT, L. S. Cinesiologia clinica para fisioterapeutas. 3 ed. Rio de Janeiro: Editora Guanabara, 2008.

LONGEN, W. C. Ginástica laboral na prevenção de ler/dort? um estudo reflexivo em uma linha de produção. Florianópolis: Universidade Federal de Santa Catarina, 2003.

LOPES, R. E. A. Eficácia da técnica de dejarnette categoria III no tratamento de hérnia discal lombar. Cascavel: Faculdade Assis Gurgacz, 2006.

MACHADO, G, F; BIGOLIN, S .E. Estudo comparativo de casos entre a mobilização neural e um programa de alongamento muscular em lombálgicos crônicos. Fisioterapia do Movimento. Curitiba, v. 23 , n. 4 , p. 545-554, out./dez. 2012

MARK, D. Fisioterapia ortopédica: exame, avaliação e intervenção. 2 ed. Porto Alegre: Artmed, 2010.

MARKES, N. R.; HALLAL, C. Z.; GONÇALVES, M. Características biomecânicas, ergonômicas e clinicas da postura sentada: uma revisão. Fisioterapia e Pesquisa. São Paulo, v. 17, n. 3, p. 270-6, jul./set. 2010. Disponível em: <http://www.scielo.br/pdf/fp/v17n3/15.pdf>. Acesso em: 20 abr. 2012.

MATTOS, D. J. S. Você sabia que é mais saudável para a coluna ficar em pé do que sentado? 2003. Disponível <http://www.pmf.sc.gov.br/arquivos/arquivos/pdf/17_08_2010_16.37.28.6acf028cba3d01c2dc63f5df5 7f33bfe.pdf> Acesso em: 11 out. 2011.

MELO, W. V. C. Avaliação ergonômica do membro superior esquerdo de operadores de trem metropolitano: uma investigação de sobrecargas no sistema osteomuscular dissertação de mestrado. São Paulo: Universidade de São Paulo - USP, 2007.

MOGNAGO, T. S. B. S. et al. Estresse, aspecto psicossocial do trabalho e disturbio musculoesqueletico em trabalhadores de enfermagem. Rev. Enferm. UERJ. Rio de Janeiro, v.17, n. 1, p.118-23, 2009.

MONTANHOLI, L. L.; TAVARES, D. M. S; OLIVEIRA, G. R. Estresse: fatores de risco no trabalho do enfermeiro hospitalar. Revista Brasileira de Enfermagem. Brasília, V. 59, n. 5, p. 661-5, 2006. Disponível em: <http://www.scielo.br/pdf/reben/v59n5/v59n5a13.pdf.> Acesso em: 11 ago. 2012.

MORAIS, D. P. Perfil dos mototaxitas da cidade de Juazeiro do Norte - CE. Juazeiro do Norte: Faculdade Leão Sampaio, 2010.

MORAIS, L. F. S. M. Os princípios das cadeias musculares na avaliação dos desconfortos corporais e constrangimento posturais em motoristas do transporte coletivo. Florianópolis: Universidade Federal de Santa Catarina, 2002. 
MOREIRA, A. M. R.; MENDES, R. Fatores de risco dos distúrbios osteomusculares relacionados ao trabalho de enfermagem. Revista Enfermagem UEFJ. Rio de Janeiro, v. 13, p. 19-26, 2005. Disponível em: <http://www.facenf.uerj.br/v13n1/v13n1a03.pdf> Acesso em: 25 set. 2012.

NATUOR, J. et al. Coluna Vertebral Conhecimentos Básicos. Etcetera Editora de Livros e Revistas, 2004. [online]. Disponível em: 〈http://www.reumatologia.com.br/PDFs/ColunaVertebral.pdf> Acesso em: 19 maio 2012.

NOGUEIRA, C. G. R. Prevalência dos sinais e sintomas osteomusculares relacionados ao trabalho em funcionários de uma construtora civil. Juazeiro do Norte: Faculdade Leão Sampaio, 2011.

OLIVEIRA, C. F. C.; VEZZA, F. M. C. A saúde dos músicos: dor na pratica profissional de músicos de orquestra no ABCD paulista. Revista Brasileira de Saúde Ocupacional. São Paulo, v. 35, n. 121, p. 33-40, 2010.

PATUSSI, A. P. Definição de critérios de avaliação ergonômica para mesas de trabalho informatizado. Porto Alegre, Universidade Federal do Rio Grande do Sul 2005.

PEREIRA, A. C. V. F.; GRAÇA, C. C. Prevalência de dor musculoesquelética relacionada ao trabalho em cirurgiões - dentistas atuantes na rede do sistema único de saúde (SUS) no município de Camaçari - BA, 2008. 21p. [online]. Disponível em: <http://www.ergonet.com.br/download/ler-dentistas.pdf> Acesso em: 24 out. 2012.

PICOLOTO, D.; SILVEIRA, E. Prevalência de sintomas osteomusculares e fatores associados em trabalhadores de uma indústria metalúrgica de canoas - RS. Ciência e saúde coletiva. Rio de Janeiro, v. 13, n.2, pp. 507-516. 2008.

PINHO, A. M. Paralisia congênita do plexo braquial. Guarda: Universidade Beira Interior - UBI, 2012. Disponível em: http://www.fcsaude.ubi.pt/thesis/upload/11tese_de_mestrado_par.pdf. Acesso em: 18 ago. 2012.

REIS, et al. Docência e exaustão emocional. Educação e Sociedade. Campinas, v. 27, n. 94, p. 229253, jan./abr. 2006.

REIS, P. F.; REIS, D. C.; MORO, A. R. P. Mobiliário escolar: antropometria e ergonomia da postura sentada. Florianópolis: Universidade Federal de Santa Catarina, 2005. Disponível em: <http://www.luzimarteixeira.com.br/wp-content/uploads/2010/07/mobiliario-escolar-antropometria-eergonomia.pdf>. Acesso em: 11 out. 2011.

RODRIGUES, M. A. Analise do transporte coletivo urbano com base em indicadores de qualidade. Uberlândia: Universidade Federal de Uberlândia, 2008.

RODRIGUES, T. F. F. e PHILIPPI, S. T. Avaliação nutricional e risco cardiovascular em executivos submetidos a check-up. Revista da Associação Médica Brasileira. São Paulo, v. 54, n. 4, p. 322-7, 2008.

RODRIGUES, T. F. F. e PHILIPPI, S. T. Avaliação nutricional e risco cardiovascular em executivos submetidos a check-up. Revista da Associação Médica Brasileira. São Paulo, v. 54, n. 4, p. 322-7, 2008. 
RUMAQUELLA, M. R.; et al. Os efeitos da postura sentada prolongada na coluna vertebral: uma revisão. In: CONGRESSO BRASILEIRO DE PESQUISA E DESENVOLVIMENTO EM DESIGN, 8., 2008, São Paulo. Anais eletrônicos... São Paulo: Centro Universitário SENAC, 2008. Disponível em: 〈http://www.consultoriasb.com.br/artigos/ginastica-laboral3.pdf>. Acesso em: 22 mar. 2012.

SERRANHEIRA et al. Auto-referência de sintomas de lesões músculo-esqueléticas ligadas ao trabalho (LMELT) numa grande empresa em Portugal. Saúde Ocupacional. São Paulo, v. 21, n. 2, jun./dez. 2003.

SERVILHA, et al. Riscos ocupacionais na legislação trabalhista brasileira: destaque para aqueles relativos à saúde e à voz do professor. Revista da Sociedade Brasileira de Fonoaudióloga. São Paulo, v.15, n. 4, p. 505-13, 2010.

SILVA, F. de J. L.; BRAGA, L. F. A ginastica laboral na busca do bem-estar físico dos funcionários da delegacia da receita federal em Belém do Pará: uma proposta de uma cartilha explicativa. Manaus: Universidade Federal do Amazonas, 2006.

SOUSA, G. F. Índice de morbidade osteomusculares dos motoristas de transporte alternativo no complexo crajubar da região do cariri. Juazeiro do Norte: Faculdade Leão Sampaio, 2009.

TAVARES. F. de A. Estresse em motoristas de transportes coletivo urbano por ônibus. Uberlândia: Universidade Federal de Uberlândia - UFU, 2010.

TOSCANO, J. O.; EGYPTO, E. P. A influência de sedentarismo na prevalência de lombalgia. Revista Brasileira de Medicina do Esporte. São Paulo, v. 7, n. 4, jul./ago., 2001.

VIDAL. O. P. Tratamento da lombalgia em funcionários do setor de higienização de uma instituição de ensino superior do vale dos sinos através de ajustes quiropráticos. Novo Hamburgo: Universitário Feevale, 2007.

VIEIRA, J. E. A. Análise cinemática do perfil da coluna vertebral de operadores de caixa de supermercado: efeitos do modelo de checkout e peso do produto. Curitiba: Universidade Federal do Paraná - UFPR, 2004.

ZAPATER, A. R.; et al. Postura sentada: a eficácia de um programa de educações para escolares. Ciência e saúde coletiva. Rio de Janeiro, v. 9, n. 1, p. 191-199, 2004.

Como citar este artigo (Formato ABNT):

VIEIRA, A.C.C; LOPES, C.M.U.; PIRES, D.L.; ALMEIDA, G.R.P..; OLIVEIRA, G.F. Prevalência de sintomas osteomusculares em cobradores de ônibus coletivo em uma empresa na cidade de Juazeiro do Norte - CE. Id on Line Revista de Psicologia, Julho de 2015, vol.9, n.27. p. 118-153. ISSN 1981-1189.

Recebido: 08/03/2015

Aceito:08/04/2015 